\title{
Propriedades Químicas e Físicas do Esmalte de DenTes Decíduos e Permanentes
}

Tese apresentada à Faculdade de Odontologia de Ribeirão Preto da Universidade de São Paulo para obtenção do título de Doutor em Ciências.

Programa: Odontopediatria

Área de Concentração: Odontopediatria

Orientador: Profa. DRA. Regina Guenka PaLma DibB Coorientador: PROFA. DRA. MARIA CRISTINA BORSATTO

Ribeirão Preto - SP 


\section{AUTORIZAÇÃo PARA REPRODUÇÃo}

Autorizo a reprodução e/ou divulgação total ou parcial da presente obra, por qualquer meio convencional ou eletrônico, desde que citada a fonte.

Ficha Catalográfica

Gomes-Silva, Jaciara Miranda

Propriedades químicas e físicas do esmalte de dentes decíduos e permanentes. Ribeirão Preto, 2011.

83 p. : il. ; $30 \mathrm{~cm}$

Tese de Doutorado, apresentada à Faculdade de Odontologia de Ribeirão Preto/USP - Área de Concentração: Odontopediatria.

Orientador: Palma-Dibb, Regina Guenka

Coorientador: Borsatto, Maria Cristina

1. Esmalte 2. Dentes decíduos 3. Dentes permanentes 4. Propriedades químicas

5. Propriedades físicas 
FOLHA DE APROVAÇÃO

Gomes-Silva JM. Propriedades químicas e físicas do esmalte de dentes decíduos e permanentes. Tese apresentada à Faculdade de Odontologia de Ribeirão Preto da Universidade de São Paulo, para obtenção do Título de Doutor em Ciências. Área de Concentração: Odontopediatria.

Data da defesa:

\section{BANCA EXAMINADORA}

Prof. Dr.

Julgamento

Assinatura

Prof. Dr.

Julgamento

Assinatura

Prof. Dr.

Julgamento

Assinatura

Prof. Dr.

Julgamento

Assinatura

Prof. Dr.

Julgamento

Assinatura 


\section{Jaciara Miranda Gomes da Silva}

DADOS CURRICULARES

NASCIMENTO

FILIAÇÃo

1995-1998

1999-2000

2004-2007

2008-2011
01 de abril de 1977, São Paulo - SP

Cícero Gomes da Silva

Elizabeth Miranda da Silva

Curso de Graduação

Faculdade de Odontologia de Bauru da Universidade de São Paulo FOB/USP

Especialização em Odontopediatria

Fundação Bauruense de Estudos Odontológicos - Bauru/São Paulo

Curso de Pós-Graduação em Odontopediatria, nível de Mestrado

Faculdade de Odontologia de Ribeirão Preto da Universidade de São Paulo - FORP/USP

Doutorado em Ciências

Programa: Odontopediatria

Área de Concentração: Odontopediatria

Faculdade de Odontologia de Ribeirão Preto da Universidade de São Paulo - FORP/USP 
“Viver! E não ter a vergonha

De ser feliz

Cantar e cantar e cantar

A beleza de ser

Um eterno aprendiz...

Somos nós que fazemos a vida Como der, ou puder, ou quiser...

É a vida, é bonita

E é bonita..."

(Gonzaguinha) 


\section{A Deus,}

“...Graças Te dou, visto que por modo assombrosamente maravilhoso me formaste;

as Tuas obras são admiráveis,

e a minha alma o sabe muito bem...

Os Teus olhos me viram a substância ainda informe, e no Teu livro foram escritos todos os meus dias, cada um deles escrito e determinado, quando nenhum deles havia ainda..."

SI 139:13-16

"Não a nós, não a nós, mas ao Teu nome dá glória, por amor da Tua misericórdia e Tua fidelidade."

SI 115:1.

Agradeço Senhor por Tua fidelidade e misericórdia em minha vida!!! 


\section{Aos meus pais,}

Por me ensinarem desde muito pequena a amar a Deus e ao meu próximo, pelas inúmeras vezes que renunciaram seus sonhos para viverem os meus, pelo incentivo, pelo carinho e amor incondicionais.

Amo vocês e agradeço a Deus todos os dias por serem meus pais!

"Há momentos na vida em que se deveria calar... e deixar que o silêncio falasse ao coração; Pois há sentimentos que a linguagem não expressa... e há emoções que as palavras não sabem traduzir..."

\section{Ao Sérgio, meu marido,}

"Ainda bem que você vive comigo Porque senão como seria esta vida? Sei lá, sei lá

Se há dores tudo fica mais fácil

Seu rosto silencia e faz parar Neste mundo de tantos anos, entre tantos outros Que sorte a nossa, hein?

Entre tantas paixões Este encontro, nós dois, esse amor(...)" Vanessa da Mata/Liminha

Obrigada pela paciência, por suprir meus momentos de ausência com a nossa princesinha, por seguir sempre ao meu lado. Meu melhor amigo é o seu amor. Amo você!!! 
A minha filha, Maria Luisa,

"...Por ela é que eu faço bonito Por ela é que eu faço o palhaço Por ela é que saio do tom Por ela é que o show continua E quando ela está nos meus braços As tristezas parecem banais O meu coração aos pedaços Se remenda prum número a mais..."

Chico Buarque

Meu mais puro e pleno amor... Obrigada filha por tão pequena entender minhas ausências...

Agradeço a Deus por ter me concedido a benção de vivenciar o milagre da vida e o de "ser mãe", o de sentir que seu coração não bate mais em você.

Aos meus irmãos (Lucão, Luquinha, Isaque, Filipe, Jonatas e Marco Túlio) e minha cunhada Mariane,

Por terem tornado meus dias mais alegres, por compartilharem comigo as angústias e vitórias. Muito Obrigada. 
Aos meus sobrinhos, Tiago e Henrique,

Obrigada pela benção de ser "tia". Porque só uma TIA pode dar abraços como uma MÃE, guardar segredos como uma IRMÃ, aconselhar como uma AMIGA e permitir como uma AVÓ. Amo vocês.

Aos meu sogro e minha sogra,

Obrigada por sempre me verem como uma filha, vibrando com as minhas conquistas. 


\section{AGRADECIMENTOS ESPECIAIS}

\section{A Profa. Dra. Regina Guenka Palma-Dibb, minha orientadora,}

Obrigada pelo carinho e pela confiança. Pela competência, dignidade e ética com que conduz sua vida e seu trabalho. Re, você é uma verdadeira mãezona para todos, inclusive para mim: um enorme coração, senso de justiça e compreensão. Obrigada por entender minhas ausências (trabalho, família...) e por me permitir ser uma amiga. Tenho certeza que sempre terei sua mão estendida para mim. Agradeço também a sua família (Alessandro, Sophia, Stephanie e Oliver) por dividirem a mãe e a esposa um pouco comigo. Levarei seu entusiasmo e ensinamentos sempre comigo. Muito Obrigada!!!!

A Profa. Dra. Maria Cristina Borsatto, minha coorientadora,

Cris, você é um exemplo de pesquisadora e profissional por sua capacidade, sabedoria, ética e dignidade. Mas, acima de tudo você é um exemplo de pessoa pela sua alegria de viver. Nestes anos de convívio passamos por momentos bons e outros nem tantos, mas com certeza o que fica é o sentimento sincero que temos em nós: carinho e amizade. Muito obrigada por confiar no meu trabalho, por estar sempre disposta a me orientar e por tornar esta jornada mais suave. Quero sempre ter por perto sua risada mais gostosa e sua alegria escandalosa...

"Os verdadeiros sábios se dão a conhecer pelos bons princípios de seus atos, pela intocável moral de suas atitudes e pelo fato de servirem de exemplo dos ensinamentos que transmitem". 


\section{A Carolina Paes Torres Mantovani,}

Cá, tem um versículo na bíblia que diz: "em todo o tempo ama o amigo e na angústia nasce o irmão." Obrigada por compartilhar o amor de amiga e a confiança de irmã. Por me permitir participar da sua vida e da sua família. Sem você teria sido muita mais árdua a caminhada... e olha que não foi fácil!! Mas, vencemos!!! Essa conquista é NOSSA!!!! Parceiras, em todos os momentos!!! Que Deus abençoe sua linda família!!!

\section{A Fátima Aparecida Rizóli,}

Muitas pessoas passam pela vida da gente, mas só os verdadeiros amigos deixam marcas... Fá, com certeza já tenho muito de você em mim... e com muito orgulho. Você é uma daquelas pessoas que vale a pena conhecer: sua força e sua garra. Mas, com um coração cheio de ternura. Obrigada por dividir o "pão" de cada dia nestes anos de convivência... Por me permitir os seus cuidados. Minha amiga, se puder de alguma forma retribuir tanto carinho... Você com certeza se tornou alicerce do meu encanto pela vida. Obrigada!

\section{A Renata Pereira Ramos,}

Obrigada por caminhar ao meu lado por tantos anos (desde a faculdade) e sempre me incentivar com seu apoio, generosidade e amizade sinceros. Obrigada por me abrir as portas desta faculdade e pelo pronto auxílio profissional sempre que precisei. Nestes mais de quinze anos de convivência, muita coisa mudou (cada ruginha tem uma história), mas o carinho e admiração que tenho por você aumentam a cada dia. Que Deus a abençoe sempre!!! 


\section{A Profa. Dra. Maria Angélica Hueb de Menezes Oliveira}

Obrigada pela amizade sincera. Minha admiração por você vai além do profissionalismo, sua capacidade de se doar não tem limites. Que você me permita estar sempre ao seu lado, pois seu entusiasmo de vida contagia todos ao seu redor.

Deus Te Abençoe!

Pela amizade que você me devota, Por meus defeitos que você nem nota... Por meus valores que você aumenta, Por minha fé que você alimenta...

Por esta paz que nós nos transmitimos, Por este pão de amor que repartimos...

Pelo silêncio que diz quase tudo, Por este olhar que me reprova mudo...

Pela pureza dos seus sentimentos, Pela presença em todos os momentos... Por ser presente, mesmo quando ausente, Por ser feliz quando me vê contente...

Por este olhar que diz "Amigo, vá em frente!"

Por ficar triste, quando estou tristonho, Por rir comigo quando estou risonho... Por repreender-me, quando estou errado,

Por meu segredo, sempre bem guardado...

Por seu segredo, que só eu conheço,

E por achar que apenas eu mereço...

Por me apontar pra DEUS a todo o instante,

Por esse amor fraterno tão constante...

Por tudo isso e muito mais eu digo

"DEUS OS ABENÇOE, MEUS QUERIDOS AMIGOS!" 


\section{Aos amigos Marta Maria Martins Giamatei Contente e Rodrigo Galo,} obrigada pela convivência e pelo incentivo constante. Obrigada pela parceria nos trabalhos e na vida. Que o caminho de vocês seja repleto de paz. Contem sempre comigo!!!

Aos meus amigos da "Prefa", Vilma Barcelos Otani, Ana Paula Vieira, Joyce Dias Missão e Prof. José Antonio Brufatto Ferraz, obrigada por dividirem todos os dias comigo de uma forma tão agradável. Por sempre estarem dispostos a me ajudar. Por suprirem minhas ausências. Muito Obrigada!

Aos amigos Alessandra Afonso Corrêa, Patrícia Marchi, César Penazzo Lepri, Walter Raucci Neto e Marcelo Azenha, obrigada por entenderem meu "jeito" de ser e estarem sempre dispostos a me auxiliarem com um sorriso no rosto.

À Profa. Dra. Kranya Victoria Serrano Díaz, obrigada pelo carinho e conselhos. Você faz parte da minha vida "forpiana" desde o primeiro dia... sempre disposta a me ouvir. Obrigada, Kran!

Ao Prof. Dr. Paulo Nelson-Filho, pelo exemplo de professor e pesquisador que norteiam minha vida acadêmica. Pela orientação constante durante minha pós-graduação, em todos os sentidos. Obrigada!

À Profa. Dra. Alexandra Mussolino de Queiroz, obrigada pela atenção e carinho à mim dispensados por todos estes anos. Muito obrigada, Danda! 
À Profa. Dra. Aldevina Campos de Freitas, exemplo de profissionalismo e humanidade. Seu entusiasmo contagia a todos seus eternos alunos. Obrigada pela oportunidade de conviver com você!

À Profa. Dra. Raquel Assed Bezerra da Silva, pelo exemplo de determinação e competência. Raquel, obrigada por sempre me acolher de forma tão afável.

Ao Profs. Drs. José Tarcísio Lima Ferreira e Fábio Lourenço Romano, pelo estarem sempre dispostos a me auxiliar no que for preciso. Muito Obrigada!

Ao Profas. Dras. Juliana Jenjiroba Faraoni Romano e Andiara de Rossi, pelas valiosas contribuições na qualificação do Projeto de Pesquisa. Muito Obrigada!

Ao Prof. Dr. Luis Eduardo Silva Soares, do Laboratório de Espectroscopia Vibracional Biomédica - LEVB da Universidade do Vale do Paraíba, pela disposição em colaborar com este trabalho.

Ao Prof. Dr. Luiz Carlos Pardini, obrigada pela colaboração imprescindível na parte experimental desta tese, com entusiasmo e disposição em ensinar. Espero que esta parceria se estenda em outros projetos.

Aos amigos Cíntia Guimarães de Almeida e ao Prof. Dr. Luciano Bachman, obrigada pelo auxílio na parte experimental deste trabalho, pelas portas sempre abertas e pela paciência para esclarecer minhas dúvidas. Obrigada 
porque nossa convivência se estende além dos muros da universidade, numa amizade gostosa e sincera.

Ao Sr. Reginaldo Santana da Silva, do Departamento de Odontologia Restauradora da Faculdade de Odontologia de Ribeirão Preto da Universidade de São Paulo, pelo auxílio na execução dos procedimentos experimentais e pela alegria da companhia.

Aos técnicos Edson Volta e Ricardo de Souza Antunes do Laboratório LIPEN, da Faculdade de Odontologia de Ribeirão Preto da Universidade de São Paulo, pelo auxílio na execução dos procedimentos experimentais, com muita competência e dedicação.

As amigas Cristhiane Ristum Bagatin Rossi e Soraya Cheier Dib Gonçalves, minhas companheiras desde o mestrado. Obrigada pela amizade!

Aos colegas de Pós Graduação em Odontopediatria da Faculdade de Odontologia de Ribeirão Preto da Universidade de São Paulo, Camila Scatena, Cíntia Guimarães de Almeida, Danielle Torres Azevedo, Luciane Almeida do Carmo, Marcela Martin Del Campo Fierro, Paula Dariana Fernandes Ferreira, Rodrigo Alexandre Valério, Talitha de Siqueira Mellara, Elaine Machado Pingueiro, Fernanda Regina Ribeiro Santos, Iliana Ferraz Sabbatini, Késsia Suênia Fidelis de Mesquita, Ligia Maria Napolitano Gonçalves, Carolina Paes Torres Mantovani, Cristhiane Ristum Bagatin Rossi, Cristiane Tomaz Rocha, Fabrício Kitazono de Carvalho, Maristela Soares Swerts Pereira, Regina Aparecida Segatto Saiani, Rodrigo Teixeira Macri, Soraya Cheier Dib Gonçalves, Cristina Bueno Brandão, Kleber Cortês Bonifacio, Larissa Moreira Spinola de Castro, Leonardo Bíscaro Pereira, Marcela C. D. Andrucioli, Marina Fernandes de Sena, Marta Maria 
Martins Giamatei Contente, Walter Raucci Neto, Maya Fernanda Manfrin Arnez e Milena Silva Campos, pela agradável convivência que tivemos.

A Clínica de Pacientes Especiais da Faculdade de Odontologia de Ribeirão Preto da Universidade de São Paulo, nas pessoas de seus funcionários pela oportunidade da convivência diária, que com certeza levarei pelo resto de minha vida na memória e no coração.

Aos docentes do Departamento de Clínica Infantil, Odontologia Preventiva e Social da Faculdade de Odontologia de Ribeirão Preto da Universidade de São Paulo, Profa. Dra. Sada Assed, Profa. Dra. Léa Assed Bezerra da Silva, Profa. Dra. Aldevina Campos de Freitas, Prof. Dr. Paulo Nelson-Filho, Profa. Dra. Alexandra Mussolino de Queiroz, Profa. Dra. Kranya Victória Díaz Serrano, Profa. Dra. Maria Cristina Borsatto, Dra. Profa. Raquel Assed Bezerra da Silva, Dra. Profa. Mírian Aiko Nakane Matsumoto, Prof. Dr. José Tarcísio Lima Ferreira, Prof. Dr. Adílson Thomazinho, Profa. Dra. Maria Bernadete Sasso Stuani, Profa. Dra. Maria da Conceição Pereira Saraiva, Prof. Dr. Fábio Lourenço Romano e Profa. Dra. Andiara De Rossi, pela atenção, orientação, convivência harmoniosa e ensinamentos que recebi.

Aos funcionários do Departamento de Clínica Infantil, Odontologia Preventiva e Social da Faculdade de Odontologia de Ribeirão Preto da Universidade de São Paulo, Micheli Cristina Leite Rovanholo, Filomena Leli Placciti, Francisco Wanderley Garcia de Paula e Silva, Carolina Paes Torres Mantovani, Marco Antonio dos Santos, Carmo Eurípedes Terra Barretto, Dorival Gaspar, Nilza Letícia Magalhães, Fátima Aparecida Rizoli, Fátima Aparecida Jacinto Daniel, Renata Aparecida Fernandes e Matheus Morelli 
Zanela. Obrigada pelos sorrisos, carinho e dedicação. Com certeza estes anos se tornaram mais agradáveis com vocês por perto!

Aos funcionários da Faculdade de Odontologia de Ribeirão Preto da Universidade de São Paulo: Benedita Viana Rodrigues, Cleber Barbosa Rita, Fátima Aparecida Jacinto Daniel, José Aparecido Neves do Nascimento, José Carlos Ferreira Junior, José Henrique Loureiro, Julio César Souza da Matta, Renata Cristina Rosa, Vera Ribeiro do Nascimento e Carolina Fragoso Motta. Obrigada pela mão sempre estendida, pelo bom humor e carinho que me dedicam, dia após dia.

As funcionárias da Seção de Pós-Graduação da Faculdade de Odontologia de Ribeirão Preto da Universidade de São Paulo, Isabel Cristina Galino Sola e Regiane Cristina Moi Sacilotto, por sempre estarem prontas a nos atender com carinho.

À Faculdade de Odontologia de Ribeirão Preto da Universidade de São Paulo, na pessoa do atual diretor Prof. Dr. Osvaldo Luiz Bezzon e do Vice-Diretor Prof. Dr. Valdemar Mallet da Rocha Barros.

À Coordenação do Curso de Pós-Graduação em Odontopediatria da Faculdade de Odontologia de Ribeirão Preto da Universidade de São Paulo, na pessoa da Coordenadora Dra. Profa. Léa Assed Bezerra da Silva, pela oportunidade de ser aluna deste programa do qual sinto enorme orgulho. Muito obrigada. 
Aos meus pacientes "especiais", motivo da minha busca pelo conhecimento. Com vocês me sinto realmente feliz e realizada no exercício da Odontologia. $O$ sorriso de vocês me faz sentir uma dentista "especial". Meus verdadeiros "super-heróis", guerreiros pela vida.

A todos que de alguma forma contribuíram para a concretização desse trabalho. Muito obrigada e que Deus abençoe a todos de uma forma muito especial!!! 


\section{Resumo}

Gomes-Silva JM. Propriedades químicas e físicas do esmalte de dentes decíduos e permanentes [tese]. Ribeirão Preto: Faculdade de Odontologia de Ribeirão Preto da Universidade de São Paulo; 2011.

A exata composição e a micromorfologia do esmalte de dentes decíduos ainda são pouco estudadas e conhecidas, e a literatura existente apresenta achados controversos. Os resultados de pesquisas realizadas em dentes permanentes são frequentemente extrapolados para dentes decíduos, sendo que a maioria dos trabalhos explora estes substratos de maneira isolada. É necessário, portanto, conhecer a composição e a estrutura do esmalte de dentes decíduos e determinar em quais aspectos este tecido realmente difere do esmalte de dentes permanentes. A comparação dos dois substratos é fundamental para que sejam estabelecidos protocolos preventivos e restauradores, bem como no desenvolvimento de materiais e técnicas específicos e efetivos para dentes decíduos e permanentes. Assim, o objetivo do presente estudo foi realizar uma análise comparativa in vitro do esmalte de dentes decíduos e permanentes, avaliando suas propriedades físicas e químicas. As propriedades químicas foram avaliadas por meio das análises de mapeamento de superfície do esmalte por Microfluorescência de Raios-X por Energia Dispersiva ( $\mu \mathrm{FRX})$ $(n=10)$ e Espectroscopia no Infravermelho por Transformada de Fourier (FTIR) $(n=10)$. As propriedades físicas analisadas foram Permeabilidade $(n=12)$, Microdureza $(n=12)$, Radiodensidade $(n=10)$ e Resistência Coesiva $(n=15)$. Nos testes de $\mu$ EDX e FTIR, os dados da amostra não apresentaram distribuição normal, empregando-se o teste não paramétrico de Mann-Whitney. Para os demais testes, a distribuição apresentou-se normal e homogênea. Assim, na análise de Permeabilidade os dados foram submetidos à ANOVA a um critério: tipo de substrato $(p<0,05)$ e na análise de Microtração os dados foram submetidos à ANOVA a dois critérios: tipo de substrato e direção dos prismas $(p<0,05)$. Para os dados de Radiodensidade e Microdureza, foi utilizado o teste t de Student para comparação entre as médias. Considerando-se as limitações de um estudo in vitro, os achados demonstraram que em relação às propriedades físicas, o esmalte de dentes decíduos apresentou maior permeabilidade, maior radiodensidade, menor resistência coesiva e microdureza quando comparado ao esmalte de dentes permanentes. Para as propriedades químicas avaliadas, 
constatou-se que o conteúdo em peso de cálcio (\%), fósforo (\%) e da proporção $\mathrm{Ca} / \mathrm{P}(\%)$ bem como os conteúdos de carbonato e água foram semelhantes entre os dois substratos avaliados. Portanto, as propriedades físicas do esmalte de dentes decíduos apresentaram características distintas em relação ao esmalte de dentes permanentes, apesar da semelhança nas propriedades químicas analisadas.

Palavras-chave: Esmalte, Dente decíduo, Dente permanente, Propriedades químicas, Propriedades físicas 


\section{ABSTRACT}

\section{Gomes-Silva JM. Chemical and Physical properties of the enamel of deciduous and}

permanent teeth [tese]. Ribeirão Preto: Faculdade de Odontologia de Ribeirão Preto da Universidade de São Paulo; 2011.

There is still little research and information on the precise composition and the micromorphology of the enamel of deciduous teeth, and the existing literature reveals controversial findings. The results of studies in permanent teeth are frequently extrapolated to deciduous teeth, and the majority of works explores these substrates alone. It is thus necessary to know the composition and structure of the enamel of deciduous teeth and determine in which ways this tissue actually differs from the enamel of permanent teeth. Comparison of these substrates under different aspects is fundamental to establish preventive and restorative protocols, as well as materials and techniques that are specific and effective for deciduous and permanent teeth. Therefore, the aim of the present in vitro study was to perform a comparative analysis of the enamel of deciduous and permanent teeth by evaluating its physical and chemical properties. Chemical analysis comprised enamel surface mapping by Energy Dispersive X-ray Microfluorescence $(\mu F R X)(n=10)$ and Fourier Transform Infrared Spectroscopy (FTIR) $(n=10)$. For the physical analysis, Permeability $(n=12)$, Microhardness $(n=12)$, Radiodensity $(n=10)$ and Ultimate Tensile Strength $(n=15)$ tests were performed. Data distribution and homogeneity were analyzed. In the $\mu \mathrm{FRX}$ and FTIR data distribution was not normal and the Mann-Whitney non-parametric test was used for statistical analysis. For the other tests, data distribution was normal and homogenous. Thus, one-way analysis of variance (type of substrate) was used for the Permeability; twoway analysis of variance (type of substrate and depth) was used for the Microtensile Bond Strength test $(p<0.05)$; data from Radiodensity and Microhardness test were analyzed using the Student's t-test. Considering the limitations of an in vitro investigation, the findings revealed that with respect to the physical properties, the enamel of deciduous teeth presented greater permeability and radiodensity and lower ultimate bond strength and microhardness of substrate when compared with the enamel of permanent teeth. Regarding the chemical properties, the amount of calcium, phosphorus and $\mathrm{Ca} / \mathrm{P}(\mathrm{wt} \%)$ as well as the amount of carbonate and water was similar for both types of substrates evaluated. 
Therefore, the enamel of deciduous teeth presented different physical properties compared to the permanent teeth, despite the similarity in chemical properties analyzed.

KEY-wordS: Enamel; Tooth, deciduous; Tooth, permanent; Chemical properties; Physical properties 


\section{SUMÁRIO}

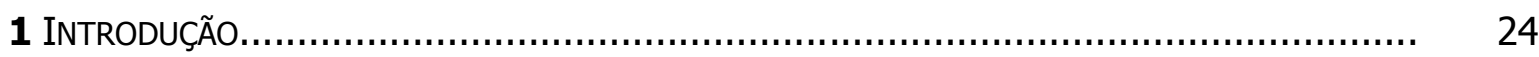

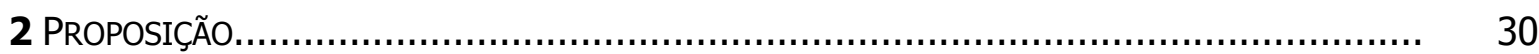

3 MATERIAL E MÉTODOS........................................................................... 32

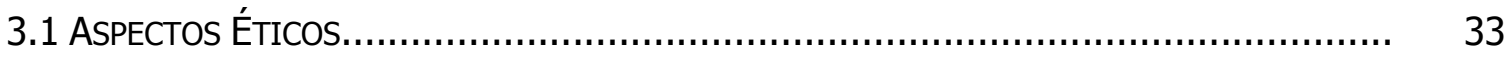

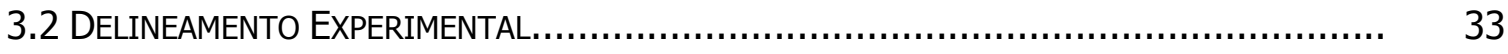

3.3 SELEÇÃO DOS DENTES......................................................................... 34

3.4 MICROFLUORESCÊNCIA DE RAIOS-X POR ENERGIA DISPERSIVA ( $\mu$ EDX)...................... 34

3.5 ESPECTROSCOPIA NO INFRAVERMELHO POR TRANSFORMADA DE FOURIER..................... 37

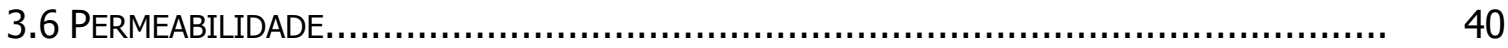

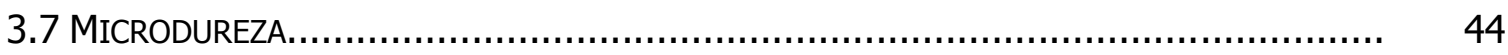

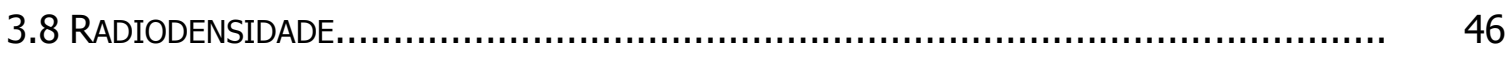

3.9 RESISTÊNCIA COESIVA (ULTIMATE TENSILE STRENGTH).................................... 49

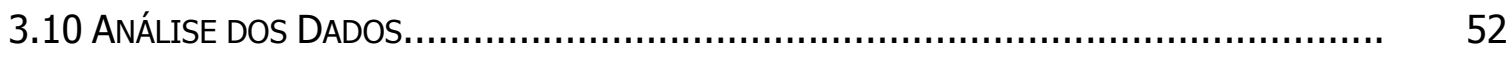

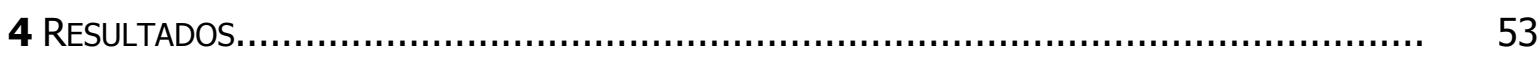

4.1 MICROFLUORESCÊNCIA DE RAIOS-X POR ENERGIA DISPERSIVA ( $\mu$ EDX) ....................... 54

4.2 ESPECTROSCOPIA NO INFRAVERMELHO POR TRANSFORMADA DE FOURIER..................... 55

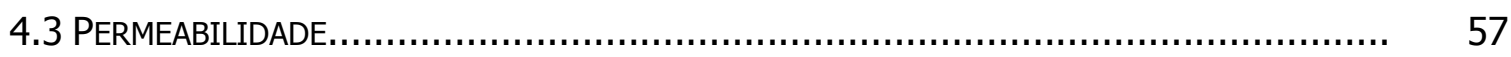

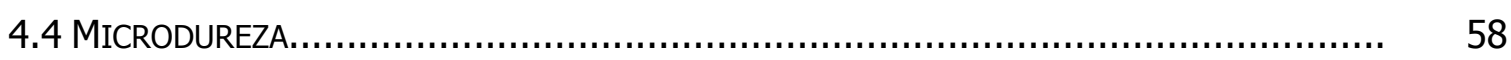

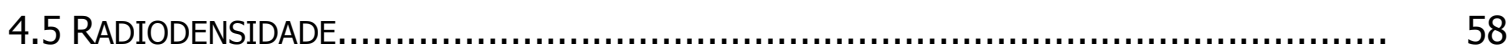

4.6 RESISTÊNCIA COESIVA (ULTIMATE TENSILE STRENGTH)................................... 59

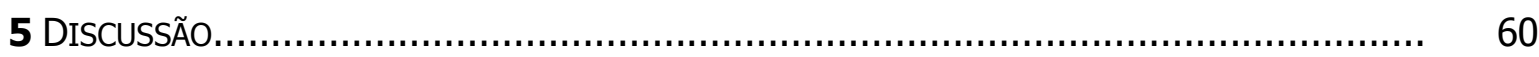

5.1 MICROFLUORESCÊNCIA DE RAIOS-X POR ENERGIA DISPERSIVA ( $\mu$ EDX) E
ESPECTROSCOPIA NO INFRAVERMELHO POR TRANSFORMADA DE FOURIER........................ 61

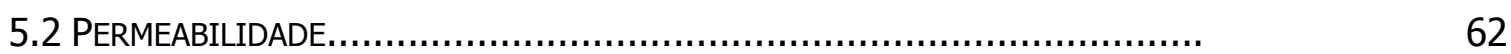

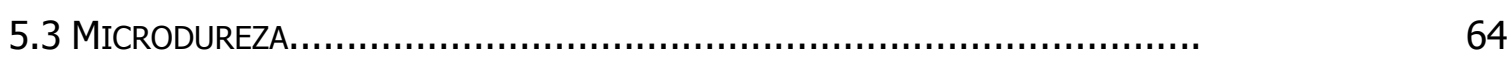

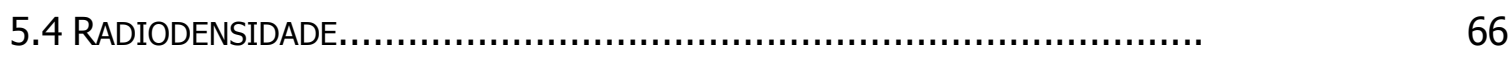

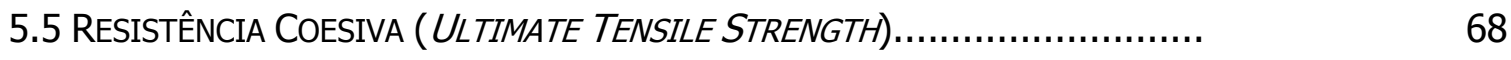

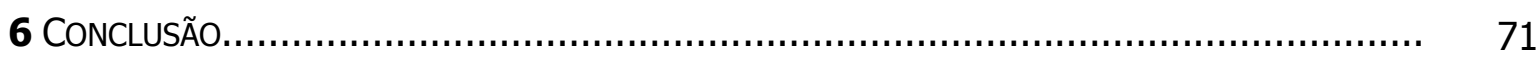

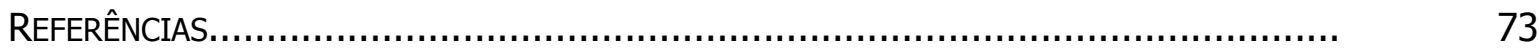

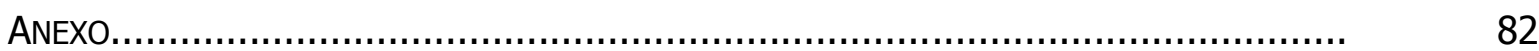




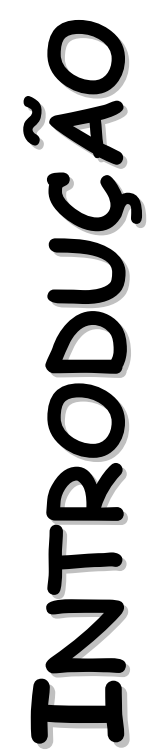




\section{INTRODUÇÃo}

Os tecidos dentários e suas estruturas de suporte são formados como resultado da interação entre o epitélio bucal e o ectomesênquima, durante a odontogênese, tendo cada tecido um processo específico de formação. Assim, amelogênese, dentinogênese e cementogênese referem-se, respectivamente, à formação do esmalte, da dentina e do cemento, tecidos dentários mineralizados (Ten Cate, 2001).

O esmalte que reveste a coroa dentária difere dos demais tecidos mineralizados por ser de origem ectodérmica, desprovido de células e incapaz de reparar-se ou remodelar-se, porém podem ocorrer interações iônicas com a cavidade bucal e mudanças em sua estrutura cristalina. É o mais duro dos tecidos mineralizados do corpo humano, apresentando 95\% em peso de conteúdo inorgânico, associado a $4 \%$ de água e $1 \%$ de material orgânico. Sua espessura varia conforme a região considerada num mesmo dente, além de variar consideravelmente de um tipo de dente para o outro (Gwinnett, 1992; Ten Cate, 2001).

A porção mineral é representada por fosfato de cálcio cristalino e apatita, nas formas hidroxi, carbonatada ou fluoretada (Gwinnett, 1992). A estrutura molecular do cristal de hidroxiapatita do esmalte contém aproximadamente 2 a $3 \%$ de carbonato. Este é incorporado durante o desenvolvimento do tecido e afeta a estabilidade química e a estrutura física do cristal, tornando-o mais ou menos suscetível às perdas minerais (SidneyZax et al., 1991; Reitznerova et al., 2000). Os elementos químicos que compõem a base do esmalte são o cálcio e o fosfato, mas variações secundárias ocorrem na sua composição e elementos químicos como alumínio, bário, estrôncio, magnésio, chumbo e vanádio também podem ser incorporados aos cristais, quando presentes durante a sua formação (Gwinnett, 1992).

Os cristais de hidroxiapatita estão distribuídos em uma organização prismática (Fejerskov et al., 1984; Eisenmann, 2001), sendo os prismas do esmalte compostos por milhares de unidades submicroscópicas denominadas cristalitos. Os cristalitos estão dispostos em um padrão tridimensional no interior de cada prisma de esmalte. A inclinação média dos cristalitos é de aproximadamente $18^{\circ}$ relativos ao longo eixo do prisma, podendo variar entre $0^{\circ}$ e $70^{\circ}$. Uma diferença marcante na angulação dos cristalitos é observada no limite entre prismas adjacentes. Esta característica morfológica confere um aumento localizado de espaço e material orgânico na região periférica dos prismas referida como bainha do prisma (Gwinnett, 1966; He e Swain, 2009). Ao redor e entre os prismas encontra-se a região de esmalte interprismático, rica em proteína e fluido do esmalte (água), resultante de 
incoerente combinação de cristais de diferentes orientações nesta área, tornando esta região menos mineralizada. Embora a união dos cristais seja firme e compacta em nível macroscópico, cada cristal é separado de seu cristal adjacente por finos espaços intercristalinos preenchidos com água ou material orgânico.

A matriz orgânica consiste em uma família característica de proteínas do esmalte, basicamente proteica de natureza não colágena, contendo alguns lipídios e carboidratos (Ten Cate, 2001). As amelogeninas correspondem a $90 \%$ das proteínas secretadas no esmalte, são hidrófobas e ricas em prolina. Em menor porcentagem estão as fosfoproteínas glicosiladas acídicas (enamelina e tufelina) e glicoproteínas sulfatadas (ameloblastina, bainhalina e amelina). As metaloproteinases e serinaproteinases são algumas das proteínas enzimáticas identificadas na matriz orgânica do esmalte, desempenhando papel importante no processo de maturação do tecido, uma vez que estas participam do processo de degradação das proteínas, principalmente das amelogeninas, permitindo o crescimento dos cristais. Embora o conteúdo orgânico corresponda a aproximadamente $1 \%$ em volume do esmalte maduro, estas proteínas circundam os cristais e influenciam o comportamento químico e físico do tecido (Smith, 1998).

A água é encontrada em quantidade significantemente maior em relação aos constituintes orgânicos (mais de $4 \%$ em volume). Aproximadamente $25 \%$ do volume de água está ligado aos cristalitos, provavelmente associado à matriz orgânica, e funciona como meio de hidratação, circundando os cristalitos que compõem os prismas de esmalte (Carlstrom et al., 1963).

Desta forma, a disposição estrutural (regiões intercristalinas e interprismáticas) viabiliza o dinamismo do esmalte com o meio bucal, tornando-o uma estrutura semipermeável (Poole et al., 1963), capaz de realizar trocas de água e íons por meio uma fina rede de vias de difusão de água e íons, que são chamadas de microporos ou poros do esmalte (Silverstone, 1970; Cevc et al., 1980). Durante a maturação do esmalte, ocorre a formação de um arcabouço cristalino, constituído de cristais com dimensões microscópicas, que expandem gradualmente lateral e longitudinalmente, ocorrendo uma diminuição gradativa dos espaços entre eles, tornando o esmalte mais denso e menos permeável. Além disso, embora o esmalte não apresente vitalidade e capacidade de neoformação, interações iônicas e mudanças em sua estrutura cristalina (maturação pós-eruptiva) podem ocorrer após o irrompimento do dente na cavidade bucal (Eisenmann, 2001). O processo de formação do esmalte do dente permanente é lento, podendo levar de 4 a 5 anos para se completar na coroa de molares, sendo que aproximadamente dois terços deste período corresponde à fase de maturação do tecido (Shellis, 1984a; Smith, 1998). 
Os prismas do esmalte possuem comprimento médio de $5 \mu \mathrm{m}$, e estão dispostos sequencialmente perpendicularmente, em sua maioria, desde a junção amelo-dentinária até a superfície externa da coroa dental (Gwinnett, 1992). O tipo de prisma ideal é o em forma de "buraco de fechadura". O corte transversal do prisma tipo "buraco de fechadura" apresenta uma cabeça arredondada e uma cauda. A diferença entre a cabeça e a cauda é a variedade na orientação dos cristais de hidroxiapatita e o eixo longitudinal do prisma. $\mathrm{Na}$ cabeça, os cristais são dispostos na grande maioria paralelamente ao longo eixo dos prismas. Na cauda, esses cristais ocorrem em um ângulo de $80^{\circ}$ a $90^{\circ}$ com o longo eixo dos prismas. Provavelmente, os cristais da cauda tocam a superfície dos cristais da cabeça dos prismas adjacentes, fazendo com que os prismas fiquem mais firmemente unidos uns aos outros (Habelitz et al., 2001).

O esmalte possui também uma região aprismática na superfície do tecido, na qual os cristais de hidroxiapatita encontram-se uniformemente arranjados, paralelos entre si, e dispostos perpendicularmente à superfície, diferindo da região prismática, subjacente, onde ocorrem variações nas orientações dos cristais (Fava et al., 1997).

Essa variação da orientação dos cristais de hidroxiapatita e dos prismas confere ao tecido a característica de anisotropia em relação à distribuição das forças mastigatórias que incidem sobre o esmalte, melhorando as propriedades físicas desta estrutura. As fraturas que normalmente ocorrem no esmalte dentário são detidas quando chegam a regiões onde os grupos de prismas se cruzam (Habelitz et al., 2001; de Las Casas et al., 2003; Giannini et al, 2004).

Devido ao seu alto conteúdo mineral e características estruturais, o esmalte pode ser considerado um sólido microporoso composto por cristais firmemente unidos o que the dá uma aparência semelhante ao vidro. A translucidez característica do esmalte permite, de acordo com a variação da sua espessura, que o dente apresente a cor da dentina (Gwinnett, 1992).

O esmalte possui um alto módulo de elasticidade e baixa resistência à tração, o que o caracteriza como um material friável (Gwinnett, 1992; Carvalho et al., 2000; Ganinni et al., 2004). Dessa maneira, trincas no esmalte são comumente encontradas clinicamente em dentes íntegros, embora fraturas mais extensas ocorram com menor frequência, pois o substrato íntegro é amparado pelas propriedades elásticas da dentina adjacente e pela alta resistência à fratura da junção amelo-dentinária (Carvalho et al., 2000; Roy e Basu, 2008).

Em relação às dentições (decídua e permanente), não há diferença na origem embriológica, mas as suas propriedades ainda não são bem conhecidas e os resultados das 
pesquisas utilizando dentes permanentes são geralmente extrapolados para os dentes decíduos.

Todavia, a literatura específica consultada tem relatado comportamentos diferentes do esmalte de dentes decíduos em comparação ao esmalte de dentes permanentes frente aos desafios ácidos, procedimentos restauradores e adesivos, bem como ao estresse mecânico (Amaechi et al., 1999; Hunter et al., 2000; Johansson et al., 2001; Wang et al., 2006; Marquezan et al., 2008).

Como exemplo, tem-se que lesões de erosão progrediram 1,5 vezes mais rapidamente no esmalte do dente decíduo comparado ao dente permanente (Amaechi et al., 1999). No entanto, outros trabalhos (Shimada et al., 2002; da Costa et al., 2008) descrevem valores similares de resistência adesiva ao esmalte de dentes decíduos em relação aos dentes permanentes. Ainda, resultados controversos foram observados nos comportamentos de dentes decíduos em relação aos novos materiais e técnicas terapêuticas e preventivas, como a tecnologia do laser e o uso de sistemas adesivos autocondicionantes (Marquezan et al., 2008; Swanson et al., 2008; Kornbli et al., 2009).

Mas, quais diferenças entre estes substratos seriam responsáveis pelos resultados encontrados na literatura?

Alguns autores (Mortimer, 1970; Søjun Clasen e Ruyter 1997; Low et al., 2008; Oliveira et al., 2010) compararam a estrutura do esmalte de dentes decíduos e de dentes permanentes, e relataram que o padrão de mineralização (velocidade e quantidade) do dente decíduo é cerca de $20 \%$ menor que o verificado para o dente permanente. Isto porque o dente decíduo apresenta ciclo biológico reduzido. Em média, o período de formação e mineralização da coroa de um dente decíduo é de no mínimo seis meses (incisivo central) e no máximo quatorze meses (segundo molar decíduo), enquanto a média para o dente permanente é de 3 a 5 anos (Shellis et al., 1984a; Araújo et al., 1995). Além disso, observase menor densidade de prismas no esmalte do dente decíduo em comparação ao permanente (Oliveira et al., 2010). Low et al. (2006; 2008) observaram que os cristais de hidroxiapatita são maiores e mais grosseiros no esmalte de dentes decíduos (185 nm) em relação ao dente permanente (94 nm) e apresentam maior quantidade de carbonato (Søjun Clasen e Ruyter 1997), menor mineralização e menor espessura (quase a metade da espessura do esmalte de dentes permanentes) (Mortimer, 1970; Low et al., 2008; Oliveira et al., 2010), o que conferiria uma menor resistência ácida a este tecido.

Somado a isso, autores (Fava et al., 1993; 1997) relataram a existência da camada aprismática mais espessa e uniforme, e uma maior porosidade (Silverstone, 1970) no esmalte do dente decíduo, que seria responsável por sua coloração branco-leitosa. 
Diante do exposto, pode-se observar que a literatura apresenta resultados controversos e de difícil comparação, pois não há padronização da metodologia dos estudos que avaliam a composição química, estrutura morfológica e propriedades físicas do esmalte de dentes decíduos, bem como sua comparação com os dentes permanentes. Adicionalmente, os trabalhos são escassos e relativamente antigos.

A utilização de metodologias e técnicas mais específicas e apuradas para a análise e interpretação dos resultados de estudos envolvendo esmalte de dentes decíduos e permanentes se faz necessária e a comparação dos substratos em um mesmo trabalho é essencial para a padronização do método de análise da pesquisa, permitindo uma análise mais efetiva.

Desta maneira, é necessária a realização de pesquisas para conhecer melhor as características dos tecidos dentários, para que sejam estabelecidos protocolos preventivos e restauradores, bem como materiais e técnicas específicos e efetivos para cada substrato. 
$2 \frac{1}{4}$
ज
0
0
0
0
0 


\section{Proposição}

O objetivo do presente estudo foi analisar comparativamente in vitro as propriedades químicas e físicas do esmalte de dentes decíduos e de dentes permanentes, por meio da avaliação do conteúdo de cálcio, fósforo, carbonato e água, bem como da permeabilidade, microdureza, radiodensidade e resistência coesiva destes substratos. 
2

U

$\frac{1}{2}$ 


\section{Material e Métodos}

\subsection{AsPECTOS Éticos}

O presente estudo foi inicialmente submetido à avaliação pelo Comitê de Ética em Pesquisa da Faculdade de Odontologia de Ribeirão Preto da Universidade de São Paulo, processo número 2010.1.542.58.1, recebendo parecer favorável (Anexo A).

\subsection{Delineamento EXPERIMENTAL}

O fator em estudo foi o tipo de substrato em dois níveis: esmalte de dentes decíduos e esmalte de dentes permanentes.

A amostra do experimento foi constituída de 69 corpos de prova. As variáveis de resposta quantitativas foram:

- análise da composição química por meio de:

- Microfluorescência de Raios-X por Energia Dispersiva ( $\mu$ EDX) $(n=10)$

- Espectroscopia no Infravermelho por Transformada de Fourier (FTIR) $(n=10)$

- análise das propriedades físicas por meio de:

- Permeabilidade $(n=12)$

- Microdureza $(\mathrm{n}=12)$

- Radiodensidade $(\mathrm{n}=10)$

- Resistência Coesiva (Ultimate Tensile Strength) $(n=15)$ 


\subsection{Seleção dos Dentes}

Foram selecionados incisivos e molares decíduos hígidos, com mais de dois terços de raiz e, incisivos e molares permanentes hígidos, irrompidos, armazenados por um período de até seis meses após a avulsão. Estes dentes foram cedidos pelo Banco de Dentes da Faculdade de Odontologia de Ribeirão Preto - USP.

Os dentes foram limpos com curetas periodontais, polidos com pedra pomes e água, com o auxílio de uma escova de Robinson, montada em contra-ângulo, em baixa rotação. Em seguida, foram examinados sob lupa estereoscópica, com aumento de $10 \mathrm{X}$ (Carl Zeiss, Jena, Alemanha), com o intuito de detectar alterações de estrutura ou trincas que pudessem comprometer os resultados do estudo.

\subsection{MiCROFLUORESCÊNCIA DE RAIOS-X POR ENERGIA DISPERSIVA ( $\mu$ EDX)}

Para este teste, incisivos decíduos e permanentes $(n=10)$ foram levados a um equipamento de corte seriado (Minitom: Struers A/S, Copenhagen, Dinamarca) dotado de um disco diamantado (\#7015: KG Sorensen, Barueri-SP, Brasil) refrigerado com água, e tiveram suas raízes seccionadas, $3 \mathrm{~mm}$ abaixo da junção amelo-cementária. As coroas foram fixadas em matrizes de resina acrílica, de forma que as superfícies vestibulares ficassem expostas. Os corpos de prova foram planificados, com lixas d'água aplicadas em ordem decrescente de abrasividade (\#600 a \#1200), em uma politriz (Politriz Universal Aropol 2 V: Arotec, Cotia-SP, Brasil), sob refrigeração abundante, e em seguida, foram polidos com disco de feltro embebido em pasta de alumina (Struers A/S, Copenhagen, Dinamarca) de granulações 0,3 $\mu \mathrm{m}$ e 0,05 $\mu \mathrm{m}$. Os espécimes foram então levados à cuba ultrassônica (Ultrasonic Clearner T-1449-D: Odontobrás Ind. e Com., Ribeirão Preto-SP, Brasil) durante 5 min para limpeza da superfície.

As superfícies em esmalte foram submetidas à análise química por meio da Microfluorescência de Raios-X por Energia Dispersiva ( $\mu \mathrm{EDX}$ ) em um equipamento da marca Shimadzu modelo $\mu E D X-1300$. A superfície da amostra foi analisada longitudinalmente por dispersão de energia da radiação, proveniente de um tubo de $\mathrm{Rh}$, posicionado a $90^{\circ} \mathrm{e}$ 
acoplado a um sistema computadorizado. A amostra foi irradiada com feixe de raios-X de raios de $50 \mu \mathrm{m}$.

A análise quantitativa dos componentes cálcio $(\mathrm{Ca})$ e fósforo $(P)$ foi realizada por varreduras em três pontos da superfície do espécime (com uma área de 0,16 $\mathrm{mm}^{2}$ para cada ponto), com um tempo de $10 \mathrm{~s}$ por região. A voltagem do tubo foi de $15 \mathrm{kV}$, com um ajuste automático da corrente e um feixe de $50 \mu \mathrm{m}$ de diâmetro. Em todas as medidas a contagem da radiação foi feita por um detector semicondutor de $\mathrm{Si}$ (Li) refrigerado por nitrogênio líquido.

Para as medidas do dente, foi utilizado, como referência de calibração, o reagente de hidroxiapatita estequiométrica sintética (Sigma-Aldrich, St. Louis-MO, EUA), grau de pureza 99,99\%. As condições analíticas foram baseadas no método dos parâmetros fundamentais. As variáveis para o cálculo da fórmula química foram estabelecidas para os pesos relativos de cálcio $(\mathrm{Ca})$ e fósforo $(\mathrm{P})$, e o elemento oxigênio $(\mathrm{O})$ foi utilizado como balanço químico. $O$ elemento hidrogênio $(H)$ não foi considerado no balanço total de massa, uma vez que a sua massa é equivalente a $0,1 \%$ do peso total da hidroxiapatita.

A proporção entre os elementos químicos presentes nas amostras foi calculada pela razão dos pesos relativos determinados por leitura direta no equipamento. O software do equipamento fornece os dados a partir do cálculo de conversão da intensidade relativa das energias de transição dos raios- $\mathrm{X}$, característicos dos elementos, para os respectivos teores em porcentagem de peso, no tempo de varredura determinado.

Após a realização do mapeamento em área, os dados correspondentes a cada amostra foram processados no software do sistema do EDX (PCMEDX Ver 1.04: Shimadzu Corp., Japão) e, em seguida, os valores da concentração em peso dos componentes cálcio e fósforo (máximo, mínimo) de cada mapeamento foram anotados e tabulados, sendo utilizados para a análise dos dados os valores médios de Ca e $\mathrm{P}$ e a proporção $\mathrm{Ca} / \mathrm{P}$.

A metodologia deste experimento está representada na Figura 1. 


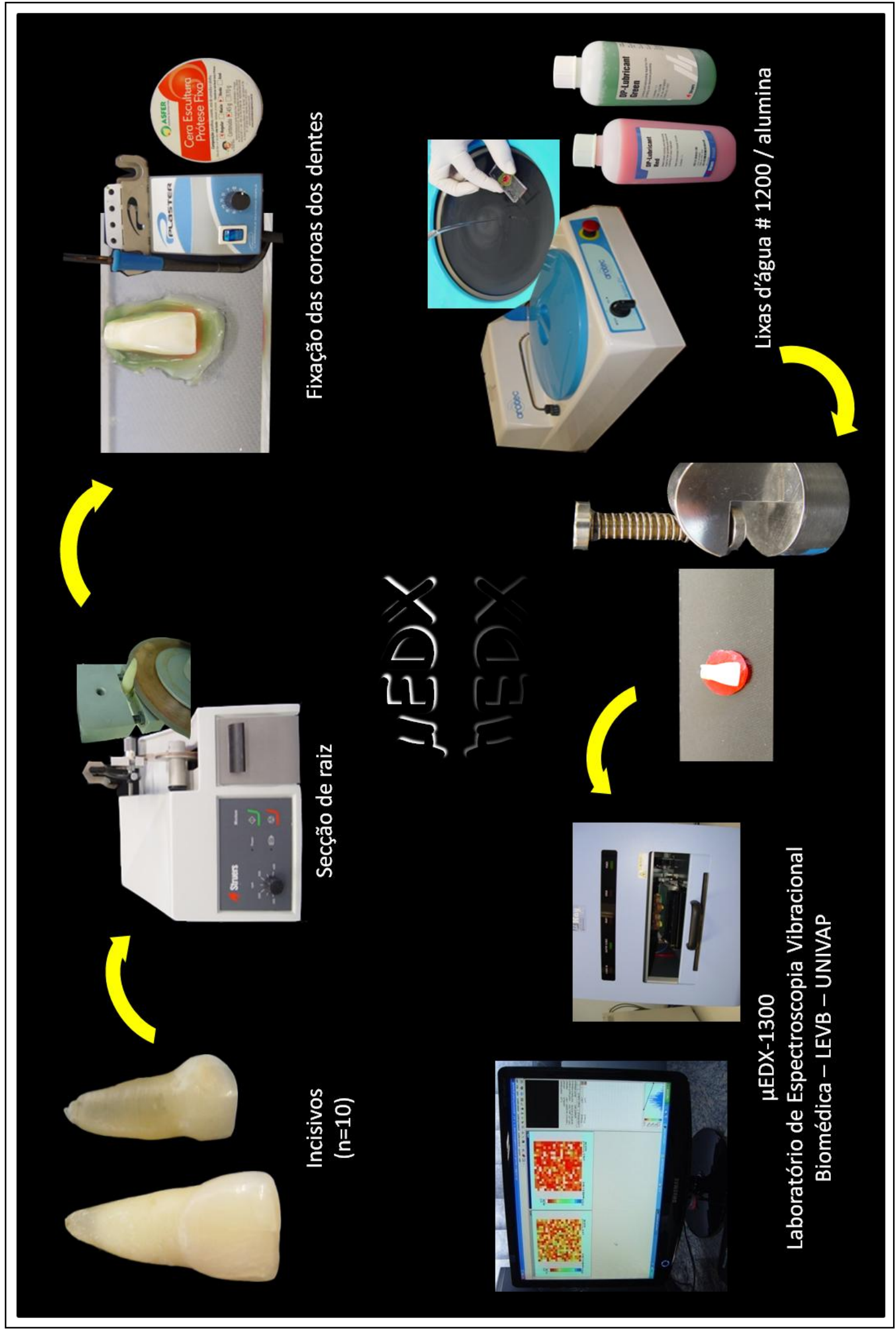

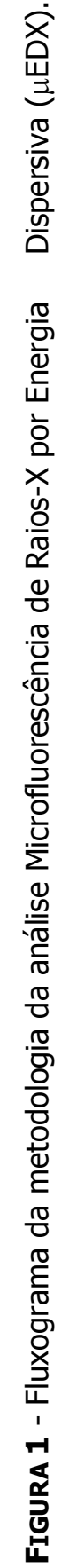




\subsection{ESPECTROSCOPIA NO INFRAVERMELHO POR TRANSFORMADA DE FOURIER (FTIR)}

Para esta análise, 10 molares decíduos e 10 molares permanentes foram levados a um equipamento de corte seriado (Minitom: Struers A/S, Copenhagen, Dinamarca), dotado de um disco diamantado (\#7015: KG Sorensen, Barueri-SP, Brasil) refrigerado com água, e tiveram suas raízes seccionadas, $3 \mathrm{~mm}$ abaixo da junção amelo-cementária. Posteriormente, as coroas dentárias foram fixadas em uma base de acrílico (lâmina de plexiglass) com auxílio de cera para escultura (Kota Ind. e Com. Ltda, São Paulo-SP, Brasil), aquecida em gotejador elétrico (Guelfi Equipamentos, Ribeirão Preto-SP, Brasil) e, por meio de um disco diamantado adaptado em máquina de corte, sob refrigeração, foram realizados cortes no sentido oclusocervical, na porção central dos molares, obtendo-se secções de $2 \mathrm{~mm}$ de espessura de cada dente. A espessura foi controlada com o auxílio de um paquímetro universal com leitura eletrônica (Digimatic Caliper: Mitutoyo, Suzano-SP, Brasil), com precisão de 0,01mm.

Para a realização desta análise, as amostras foram obtidas cortando o esmalte para se obter o pó do tecido, com o auxilio de brocas esféricas de aço montadas em baixa rotação, que foram trocadas a cada dois espécimes para garantir a eficácia do corte. Este procedimento foi realizado utilizando uma lupa estereoscópica com aumento de $10 \times$ (Carl Zeiss, Jena, Alemanha). Obteve-se uma pequena quantidade de pó o qual não foi mensurado porque a medida experimental a ser realizada no espectrômetro de FTIR independe da massa da amostra.

Após a remoção do pó de esmalte, este foi posicionado sobre uma janela de diamante num acessório de ATR (Atenuated Total Reflectence) com diâmetro de $2 \mathrm{~mm}$ (DuraScope $^{\mathrm{TM}}$ : Smiths Detection, Danbury-CT, EUA). Este acessório é acoplado ao Espectrômetro no Infravermelho por Transformada de Fourier (Nicolet-380 FT-IR Spectrometer: Nicolet, Vernon Hills-II, EUA).

A medida experimental consistiu-se na aquisição do espectro de absorbância na região entre $4000-400 \mathrm{~cm}^{-1}$ com resolução de $0,5 \mathrm{~cm}^{-1}$ e 32 varreduras para aquisição de cada espectro.

Após a aquisição dos espectros de absorbância, os mesmos foram importados e analisados pelo programa Origin 8.0 (Microcal Origin $8.0^{\circledR}$ : OriginLab, Northampton-MA, EUA). Inicialmente, selecionou-se as bandas de absorção referente ao fosfato (1220-888 $\left.\mathrm{cm}^{1}\right)$, carbonato $\left(1595-1300 \mathrm{~cm}^{-1}\right)$ e água $\left(3720-2420 \mathrm{~cm}^{-1}\right)$. 
Após a divisão, removeu-se o sinal de fundo dos espectros utilizando a ferramenta "substract straight line" do programa Origin 8.0. Realizando este procedimento para todos os espécimes e para as três regiões, cada espectro foi normalizado pela área da banda de fosfato. Após a normalização, fez-se a média da área do carbonato e água dos 10 espécimes de cada grupo experimental.

A metodologia do experimento está representada na Figura 2. 


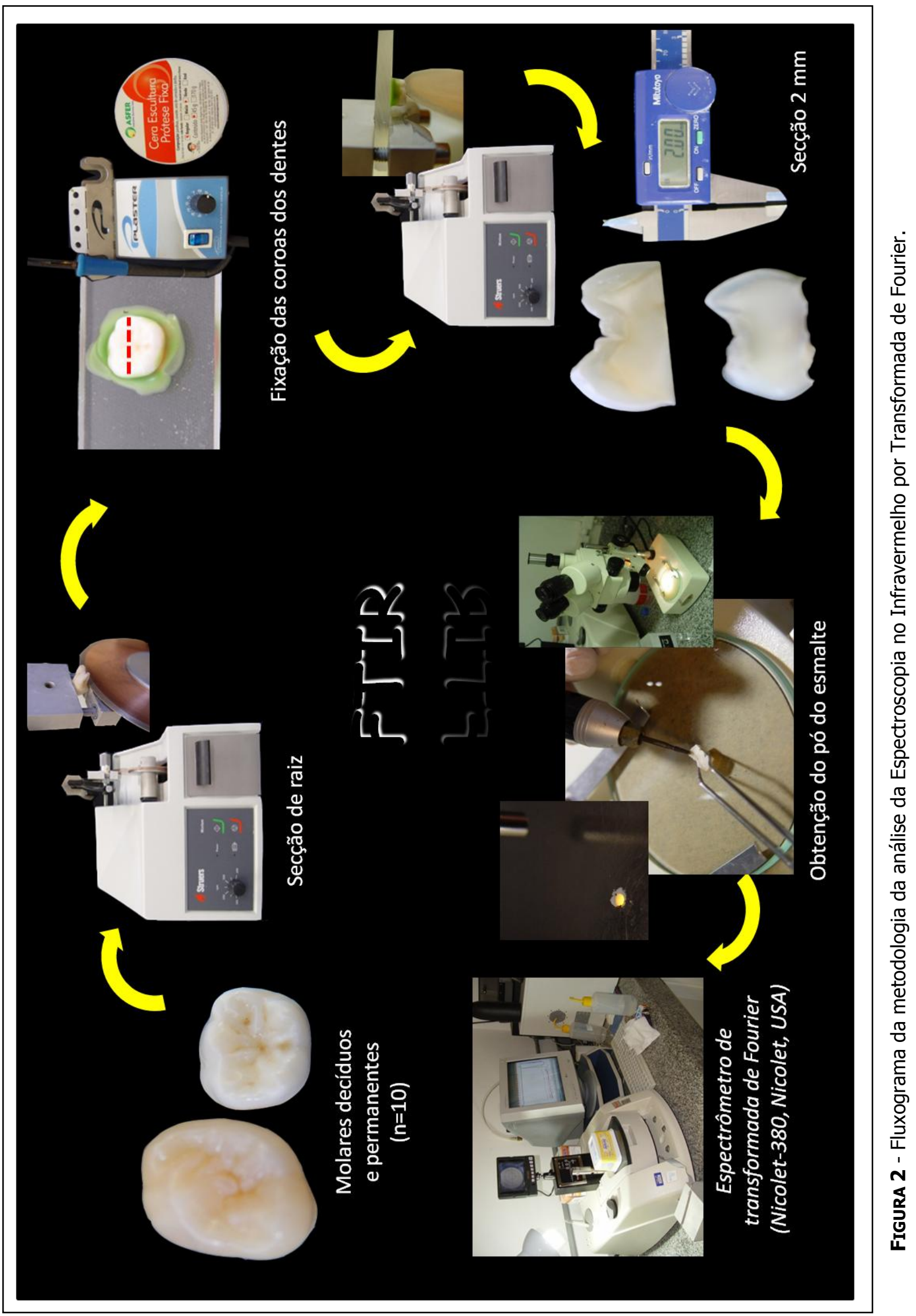




\subsection{Permeabilidade}

Para a análise da permeabilidade, 12 incisivos decíduos e 12 incisivos permanentes foram levados a um equipamento de corte seriado (Minitom: Struers A/S, Copenhagen, Dinamarca), dotado de um disco diamantado (\#7015: KG Sorensen, Barueri-SP, Brasil) refrigerado com água, e tiveram suas raízes seccionadas, $3 \mathrm{~mm}$ abaixo da junção amelocementária. Nas regiões cervicais de cada dente, áreas correspondentes às câmaras pulpares, foi realizado um selamento com resina composta Z250 (3M ESPE, St Paul-MN, EUA), em porções incrementais, fotoativadas durante $20 \mathrm{~s}$ cada. Previamente, estas áreas foram condicionadas com ácido fosfórico a 37\%, durante $30 \mathrm{~s}$, lavadas e secas com jatos de ar/água e em seguida, foi aplicado sistema adesivo Single Bond (3M ESPE, St Paul, MN, USA), em duas camadas consecutivas e fotoativado durante $20 \mathrm{~s}$. Na porção mais central e plana da superfície vestibular do esmalte da coroa foi colocada uma fita adesiva (Scotch, 3M/ESPE do Brasil Ltda., São Paulo-SP, Brasil) quadrangular, de $4 \mathrm{~mm}^{2}$ de área $(2 \times 2 \mathrm{~mm})$, com a finalidade de delimitar a área que foi exposta às soluções. Em seguida, os espécimes foram impermeabilizados com cera pegajosa e esmalte cosmético (Colorama Maybelline Cosbra Cosméticos Ltda., São Paulo-SP, Brasil), em duas camadas, e após a completa secagem, a fita adesiva foi removida para que ficasse exposta somente a área em esmalte previamente delimitada.

Os espécimes, impermeabilizados, foram imersos em um recipiente contento $10 \mathrm{~mL}$ de solução de sulfato de cobre 10\% (Merck KGaA, Darmstadt, Alemanha) por 7 dias, sendo que nos primeiros 5 min a imersão foi realizada sob vácuo. Em seguida, os espécimes foram secos com papel absorvente e imersos em $10 \mathrm{~mL}$ de solução alcoólica de ácido rubiânico $1 \%$ (Merck KGaA, Darmstadt, Alemanha), por 7 dias, sendo que nos primeiros 5 min a imersão foi realizada sob vácuo. $O$ ácido rubiânico revela os íons cobre formando um composto com coloração que varia do azul escuro ao preto, dependendo da quantidade de íons presente. $\mathrm{A}$ profundidade da infiltração destes íons quantifica a permeabilidade do substrato. Após a coloração, os espécimes foram lavados em água destilada, durante $15 \mathrm{~s}$, secos e mantidos em um recipiente vedado, com algodão embebido em amônia por um período de 7 dias, em estufa a $37^{\circ} \mathrm{C}$ (Pécora et al., 1991) para evidenciação do cobre.

Após o armazenamento em amônia, os espécimes foram lavados, secos e incluídos em blocos de resina de poliéster (Milflex Indústria Química Ltda., São Bernardo do CampoSP, Brasil) e, em seguida, foram seccionados em uma máquina de corte (Minitom: Struers A/S, Copenhagen, Dinamarca) montada com um disco diamantado (Struers A/S, 
Copenhagen, Dinamarca) para obtenção de seç̧ões transversais com espessura média de $300 \mu \mathrm{m}$. As seç̧ões foram lixadas e polidas manualmente utilizando-se lixas d'água de granulação \#600 e \#1200, com a finalidade de obter uma espessura variando de 150 a 180 $\mu \mathrm{m}$. A espessura foi controlada com o auxílio de um paquímetro universal com leitura eletrônica (Digimatic Caliper: Mitutoyo, Suzano-SP, Brasil), com precisão de 0,01 mm. Em seguida, os espécimes foram levados a uma cuba ultrassônica (Ultrasonic Clearner T-1449-D: Odontobrás Ind. e Com., Ribeirão Preto-SP, Brasil) durante 5 min e lavados abundantemente em água destilada. Foram então, observados em microscópio de luz (Carl Zeiss, Jena, Alemanha) e suas imagens analisadas utilizando-se o software AxioVision (Carl Zeiss, Jena, Alemanha), conectado a uma câmara digital (AxioCam MRc: Carl Zeiss, Jena, Alemanha). A metodologia do experimento está representada na Figura 3.

Para cada dente, foi realizada uma média dos valores obtidos em três seç̧ões. Estas medidas foram feitas por meio da mensuração da área de penetração dos íons cobre ao longo da área total de esmalte exposto (Figura 4):

Permeabilidade $(\%)=$ medida da área da penetração do íon $\times 100$

área total do esmalte analisado 


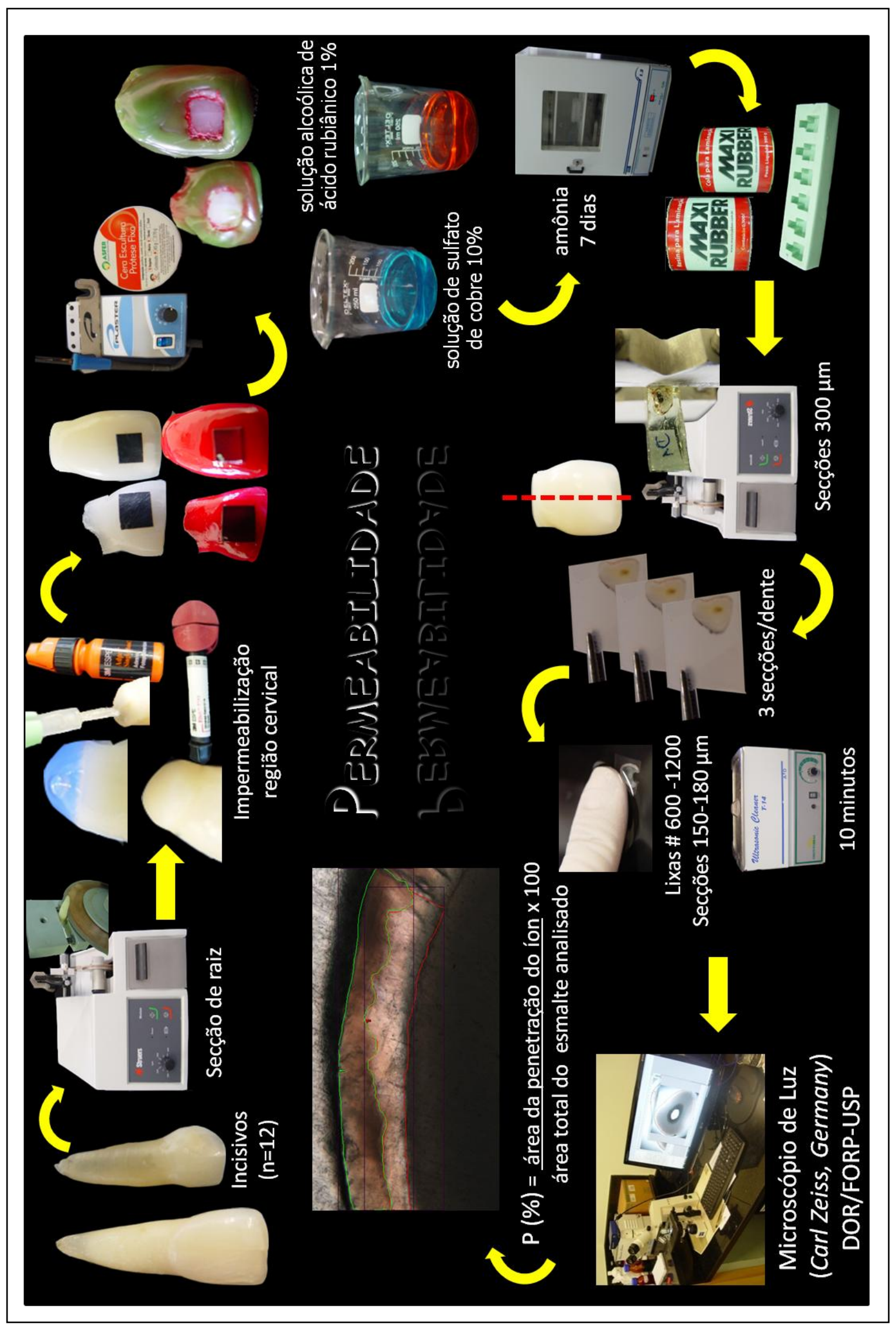

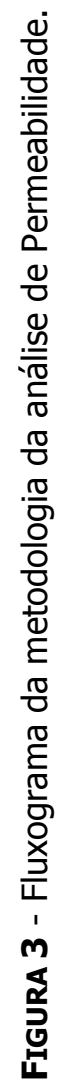



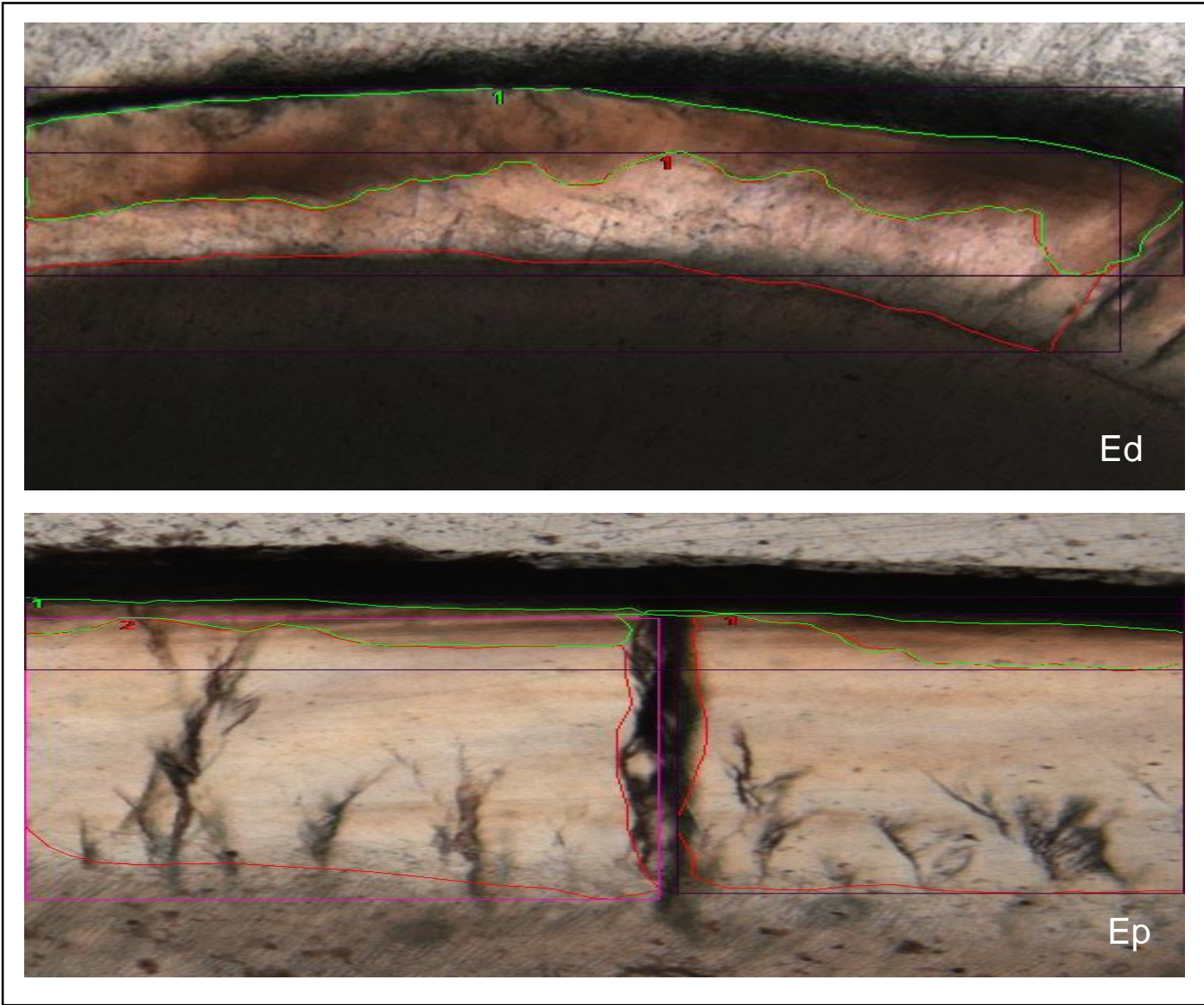

FIgURA 4 Forma de análise da permeabilidade por meio do percentual da razão da penetração do traçador com a área total do esmalte:

Ed - Esmalte de dente decíduo

Ep - Esmalte de dente permanente 


\subsection{MICRODUREZA}

Para o teste de microdureza foram utilizados 12 incisivos decíduos e 12 incisivos permanentes, que foram levados a um equipamento de corte seriado (Minitom: Struers $A / S$, Copenhagen, Dinamarca), dotado de um disco diamantado (\#7015: KG Sorensen, BarueriSP, Brasil) refrigerado com água, e tiveram suas raízes seccionadas, $3 \mathrm{~mm}$ abaixo da junção amelo-cementária. Posteriormente, os espécimes foram então levados ao ultrassom (Ultrasonic Clearner T-1449-D: Odontobrás Ind. e Com., Ribeirão Preto-SP, Brasil) durante 5 min e lavados abundantemente em água destilada.

Os dentes foram acomodados com cera utilidade em uma lâmina de vidro e com o auxílio de um paralelômetro (ElQuip, São Carlos-SP, Brasil) a região mais plana da superfície vestibular foi nivelada à base da lâmina de vidro. Foram então fixadas com cera para escultura (Kota Ind. e Com. Ltda, São Paulo-SP, Brasil), aquecida em gotejador elétrico (Guelfi Equipamentos, Ribeirão Preto-SP, Brasil), para melhor estabilização durante o teste.

A microdureza do esmalte foi avaliada utilizando-se um microdurômetro (HMV-2000/ Shimadzu Corporation, Kyoto, Japan), com um penetrador diamantado piramidal tipo Knoop, com carga estática de $25 \mathrm{gf}$, aplicada durante $20 \mathrm{~s}$, de maneira que a ponta do penetrador permanecesse paralela à superfície do esmalte.

Foram feitas cinco endentações, distribuídas aleatoriamente, com distância mínima de pelo menos $100 \mu \mathrm{m}$ entre elas. Foi obtido o valor médio da microdureza de cada dente. A metodologia deste experimento está representada na Figura 5.

Para medir as endentações realizadas, duas marcas que aparecem no visor do microdurômetro foram sobrepostas aos vértices agudos do losango correspondente à endentação, determinando o comprimento da maior diagonal e, conseqüentemente, o valor de dureza Knoop foi calculado automaticamente pelo software do equipamento, por meio da equação:

\begin{tabular}{rl|}
$\mathbf{K H N}=\frac{\mathbf{C . C}}{\mathbf{D}^{2}}$ & KHN = valor de dureza Knoop \\
& $\mathrm{C}$ (constante) $=14,230$ \\
& $\mathrm{C}=25$ gramas \\
& $\mathrm{D}=$ comprimento da maior diagonal da endentação \\
\hline
\end{tabular}




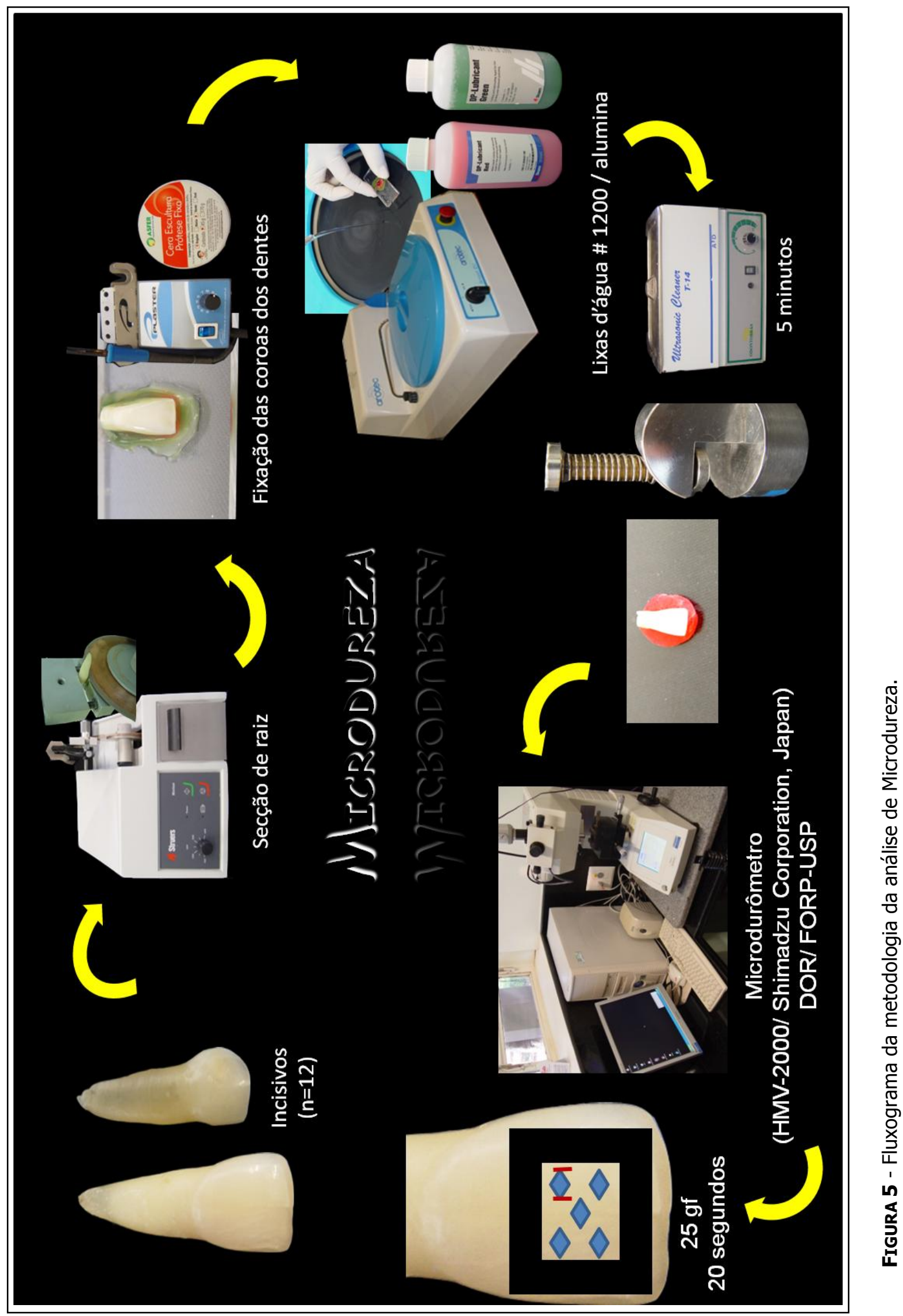




\subsection{RADIODENSIDADE}

A avaliação da radiodensidade foi realizada em 10 molares decíduos e 10 molares permanentes, que foram levados a um equipamento de corte seriado (Minitom: Struers A/S, Copenhagen, Dinamarca), dotado de um disco diamantado (\#7015: KG Sorensen, BarueriSP, Brasil) refrigerado com água, e tiveram suas raízes seccionadas, $3 \mathrm{~mm}$ abaixo da junção amelo-cementária. Posteriormente, as coroas dentárias foram fixadas em uma base de acrílico (lâmina de plexiglass) com auxílio de cera para escultura (Kota Ind. e Com. Ltda, São Paulo-SP, Brasil), aquecida em gotejador elétrico (Guelfi Equipamentos, Ribeirão Preto-SP, Brasil) e, por meio de um disco diamantado adaptado em máquina de corte, sob refrigeração, foram realizados cortes no sentido ocluso-cervical, na porção central dos molares, obtendo-se secções de $2 \mathrm{~mm}$ de espessura de cada dente. A espessura foi controlada com o auxílio de um paquímetro universal com leitura eletrônica (Digimatic Caliper: Mitutoyo, Suzano-SP, Brasil), com precisão de 0,01 mm.

Os espécimes foram posicionados sobre um filme oclusal juntamente com uma escala de alumínio (penetrômetro), medindo $10 \times 32 \mathrm{~mm}$, e escalonada em oito degraus, com espessuras incrementais de 2, 4, 6, 8, 10, 12, 14, $16 \mathrm{~mm}$, de acordo com o protocolo sugerido por Manson-Hing e Bloxom (1985). Esta escala tem a finalidade de simular, pelas nuances de tonalidades produzidas após a exposição e o processamento das radiografias, as densidades das estruturas da cavidade bucal em relação aos tecidos mineralizados e moles, para a análise laboratorial da qualidade da imagem radiográfica e constatar a homogeneidade dos procedimentos além de detectar as possíveis variações das técnicas e processamentos radiográficos.

Foi realizada uma padronização da posição dos espécimes e da escala de alumínio sobre a película radiográfica. A escala foi colocada no centro da película e cinco espécimes foram posicionados acima e cinco posicionados abaixo desta, de maneira a padronizar que a superfície mesial de cada espécime estivesse sempre voltada para a escala. Foram utilizados filmes oclusais (Insight-Kodak: Carestream Health Inc., Rochester-NY, EUA) do grupo de sensibilidade "E". Estes filmes foram mantidos sob refrigeração, conforme recomendação do fabricante, e retirados da mesma com antecedência suficiente para adquirirem a temperatura ambiente antes de sua exposição à radiação. Para a tomada radiográfica foi utilizado um aparelho de Raios X (Siemens Heliodent 60B, São Paulo-SP, Brasil) com cilindro localizador com abertura central de $11 \mathrm{~mm}$ de diâmetro, com $60 \mathrm{Kvp}, 10 \mathrm{~mA}$, com o tempo de exposição de 0,10 s. 
O cilindro localizador foi posicionado perpendicularmente aos objetos a serem radiografados de modo que a distância foco-filme fosse de $20 \mathrm{~cm}$, permitindo assim, que o feixe de radiação incidisse perpendicularmente aos objetos radiografados e ao filme radiográfico. Após a realização das tomadas radiográficas, os filmes foram submetidos ao processamento automático de revelação (A/T 2000 XR: Air Techniques Inc., Melville-NY, EUA), seguindo as recomendações do fabricante, em relação ao método de processamento tempo/temperatura.

Após a sensibilização e processamento das películas, foram realizadas leituras das densidades ópticas por meio de um fotodensitômetro (Gafchromic, Victoreen-Moedling, Austria) com feixe de luz colimado para $1 \mathrm{~mm}$ de diâmetro. A leitura do fotodensitômetro varia de 0,00 (passagem total do feixe de luz) a 4,36 (bloqueio total do feixe de luz). Três examinadores calibrados realizaram análise cega das imagens dos espécimes e da escala de alumínio, individualmente e em diferentes dias. Os valores obtidos foram anotados em tabelas.

Inicialmente, foram realizadas duas medidas referentes a cada degrau da escala de alumínio, para em seguida serem feitas as leituras da densidade óptica de cada espécime. Foi obtida uma medida da região mesial, uma da região central e uma da região distal, obtendo-se os valores de densidade óptica de cada dente pela média das três regiões analisadas. A metodologia deste experimento está representada na Figura 6. 


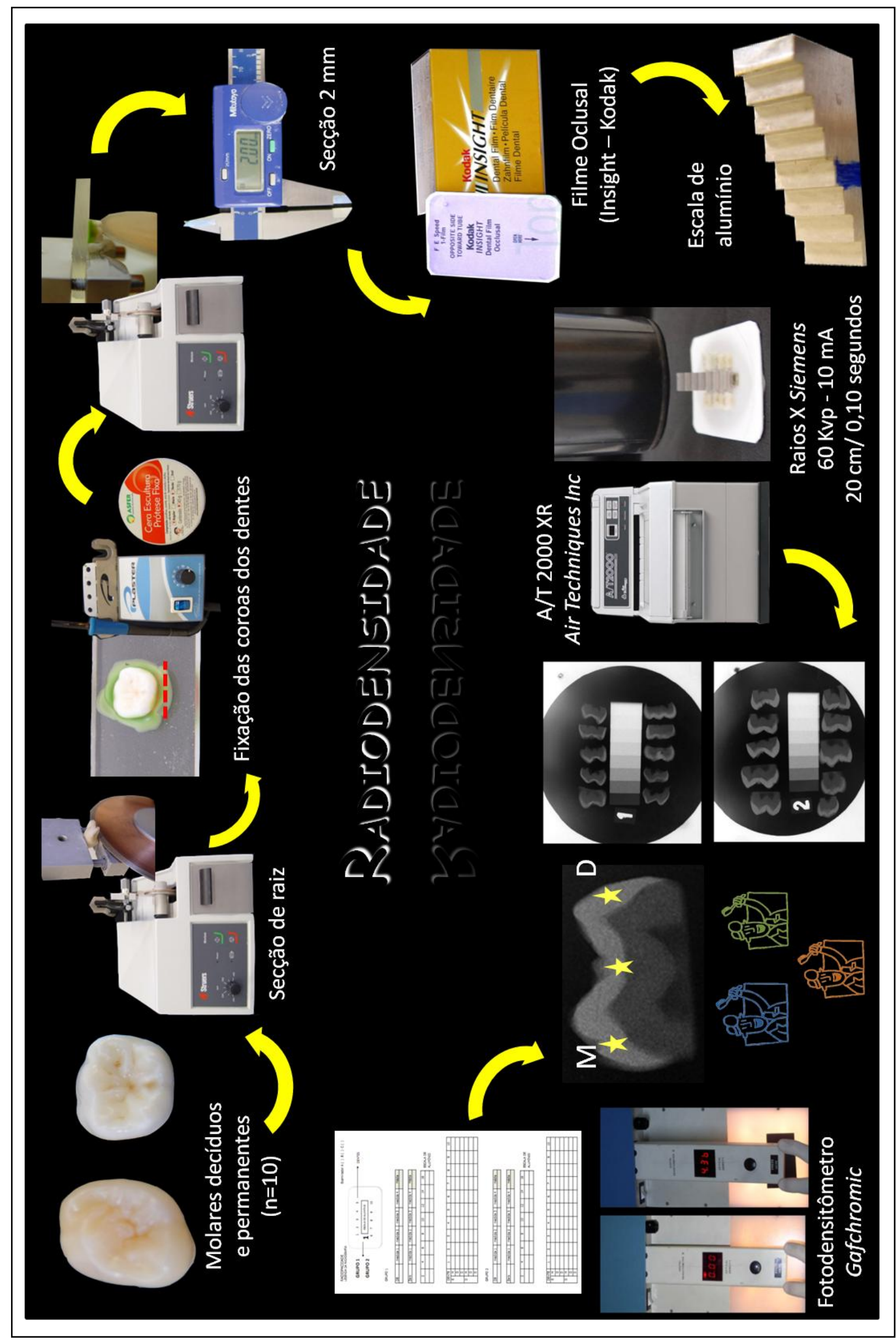

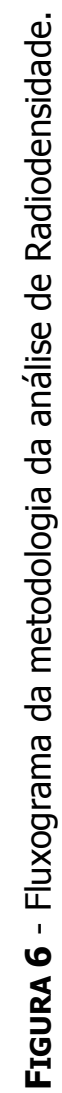




\subsection{ResistênCia Coesiva (Ultimate Tensile StRength)}

A análise da resistência coesiva do esmalte foi realizada por meio do teste de microtração. Foram selecionados 15 molares decíduos e 15 molares permanentes. A porção radicular, foi removida $3 \mathrm{~mm}$ abaixo da junção amelo-cementária com um disco diamantado (\#7015: KG Sorensen, Barueri-SP, Brasil) montado em uma máquina de corte (Minitrom: Struers A/S, Copenhagen, Dinamarca).

As superfícies oclusais foram condicionadas com ácido fosfórico a 37\%, durante $30 \mathrm{~s}$, lavadas e secas com jatos de ar/água e em seguida, foi aplicado o sistema adesivo Single Bond (3M ESPE, St Paul-MN, EUA), em duas camadas consecutivas e fotoativadas durante 20 s. Foram então, confeccionados "platôs" de resina compostas Z250 (3M ESPE, St. Paul-MN, EUA), em porções incrementais, fotoativadas durante $20 \mathrm{~s}$ cada, com a finalidade de aumentar a porção coronária para facilitar a confecção das secções. Considerando o tamanho reduzido dos molares decíduos, estes "platôs" de resina foram confeccionados na porção oclusal e na região correspondente à câmara pulpar destes dentes.

Os dentes foram fixados em uma base de acrílico (lâmina de plexiglass) com auxílio de cera para escultura (Kota Ind. e Com. Ltda, São Paulo-SP, Brasil), aquecida em gotejador elétrico (Guelfi Equipamentos, Ribeirão Preto-SP, Brasil) e, por meio de um disco diamantado adaptado em máquina de corte, sob refrigeração, foram realizados cortes no sentido ocluso cervical, obtendo-se secções de aproximadamente $1 \mathrm{~mm}$ de espessura. A espessura foi controlada com o auxílio de um paquímetro universal com leitura eletrônica (Digimatic Caliper, Mitutoyo, Suzano-SP, Brasil), com precisão de 0,01 mm.

Para cada dente, foram selecionadas secções em que apresentavam o esmalte com espessura mínima de 0,5 mm em todas as faces do espécime, em média obteve 2 secções por dente, que foram distribuídas aleatoriamente em subgrupos, de acordo com a direção dos prismas de esmalte:

- Esmalte tracionado paralelamente a orientação prismática

- Esmalte tracionado perpendicularmente a orientação prismática

Separadas as secções para cada subgrupo, foram confeccionados desgastes com o auxílio de uma ponta diamantada de granulação fina (3195 FF: KG Sorensen, Cotia-SP, Brasil) montada em alta rotação, sob refrigeração, de maneira a obter áreas de aproximadamente $1 \mathrm{~mm}^{2}$. Estas pontas foram trocadas a cada dois espécimes, para garantir a eficácia do desgaste sem gerar o estresse no tecido. 
Os espécimes, selecionados para o ensaio de microtração, tiveram suas áreas medidas e conferidas, utilizando-se um paquímetro universal com leitura eletrônica (Digimatic Caliper: Mitutoyo, Suzano-SP, Brasil), com precisão de 0,01 mm, sendo descartados aqueles que tivessem a área $<0,8$ e $>1,2 \mathrm{~mm}^{2}$. Em seguida, as secções foram fixadas individualmente pelas suas extremidades ao dispositivo para a realização do ensaio de microtração, com o auxílio de adesivo instantâneo a base de cianoacrilato (Superbonder: Gel-Henkel Loctite Adesivos LTDA, São Paulo-SP, Brasil), associado ao monômero da resina acrílica para aceleração da secagem, posicionando-se o espécime paralelamente ao longo eixo da força de microtração. $O$ ensaio foi realizado em uma Máquina de Ensaio Universal (Modelo MEM 2000: EMIC Ltda., São José dos Pinhais-PR, Brasil), previamente ajustada para forças de microtração, com uma célula de carga de capacidade de $50 \mathrm{Kgf}$, a uma velocidade de $1 \mathrm{~mm} / \mathrm{min}$. No momento da fratura, o movimento foi imediatamente cessado e os dados foram coletados para cálculos posteriores. Os valores finais de resistência coesiva foram calculados, dividindo-se os valores de carga de ruptura, em Newton (N), pelas secções transversais dos espécimes, em $\mathrm{mm}^{2}$, sendo expressos em MPa. Foram desprezados os espécimes que não romperam no esmalte e aqueles que se soltaram durante $\mathrm{o}$ teste. $\mathrm{A}$ metodologia deste experimento está representada na Figura 7. 


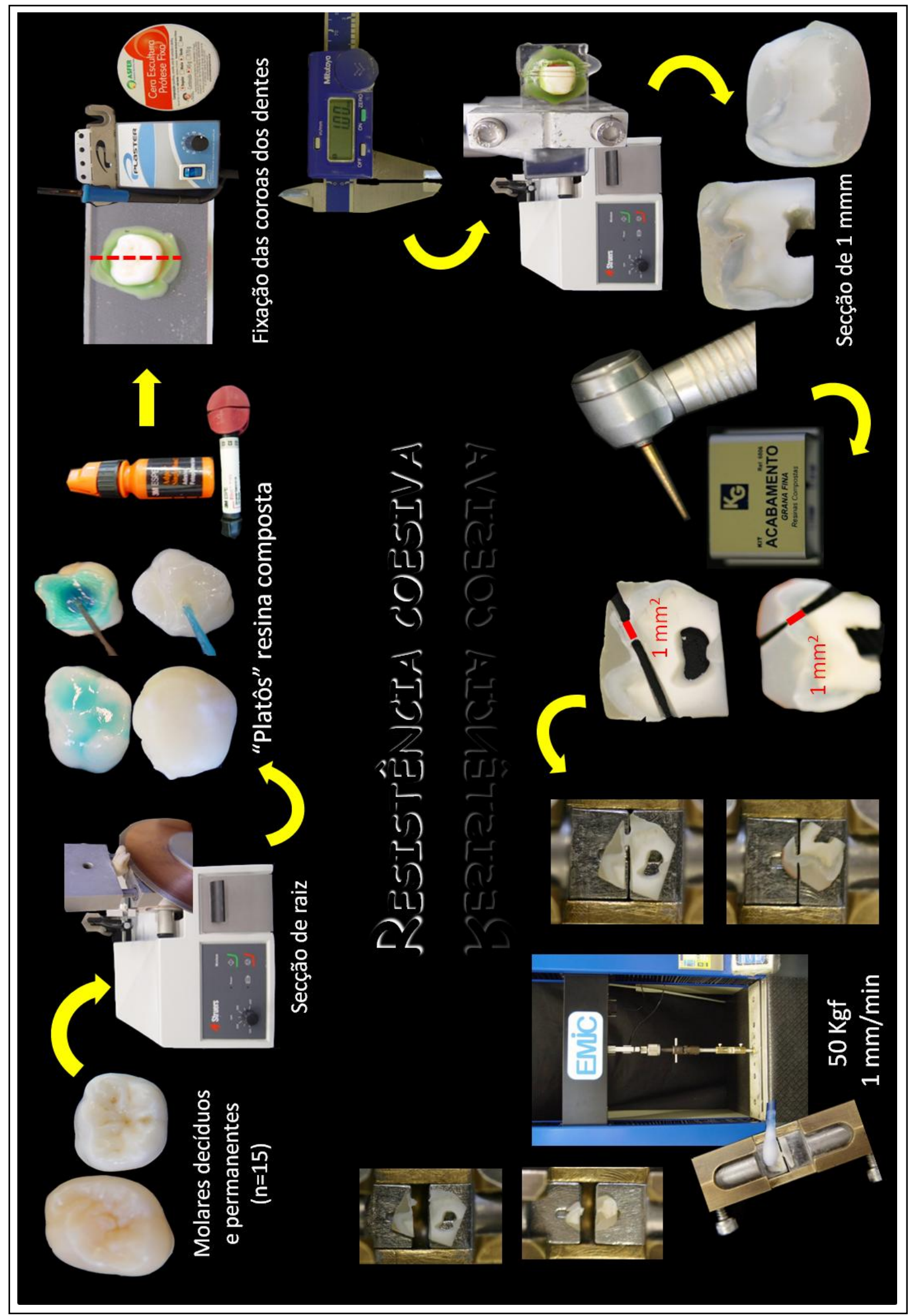

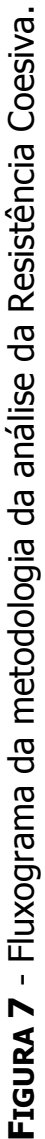




\subsection{ANÁLISE dOS DADOS}

Para o Mapeamento de Superfície por Microfluorescência de Raios-X por Energia Dispersiva foram avaliados os valores médios, de porcentagem (\%), de cálcio (Ca) e fósforo $(P)$, bem como a proporção da porcentagem em peso de $\mathrm{Ca} / \mathrm{P}$.

Para a Espectroscopia no Infravermelho por Transformada de Fourier, foram analisadas as quantidades de $\mathrm{CO}_{3}{ }^{2}$ e água, expressas em unidades arbitrárias (u.a.).

Para a análise da Permeabilidade, foi realizada mensuração da área de penetração dos íons cobre ao longo da área total de esmalte, obtendo-se valores de permeabilidade relativa do esmalte em porcentagem (\% $\mathrm{P})$.

Para a análise da Microdureza, avaliou-se a microdureza Knoop do esmalte de dentes decíduos e permanentes, em KHN. Para a análise da Radiodensidade comparou-se a densidade óptica dos substratos.

Para a análise da Microtração analisou-se a Resistência Coesiva (Ultimate Tensile Strength), de acordo com a direção da força aplicada: perpendicular e paralela à direção dos prismas, em valores expressos em MPa.

Inicialmente, os dados foram analisados quanto a sua distribuição e homogeneidade. Nos resultados obtidos no teste de $\mu$ EDX e FTIR, a distribuição não foi normal, portanto empregou-se o teste não paramétrico de Mann-Whitney. Para os demais, a distribuição apresentou-se normal e homogênea. Assim, os dados obtidos na análise de Permeabilidade foram submetidos à Análise de Variância a um critério: tipo de substrato e na análise de Microtração os dados foram submetidos à Análise de Variância a dois critérios: tipo de substrato e direção dos prismas. Para os dados de Radiodensidade e Microdureza foi utilizado o teste $t$ de Student para comparação entre as médias. 


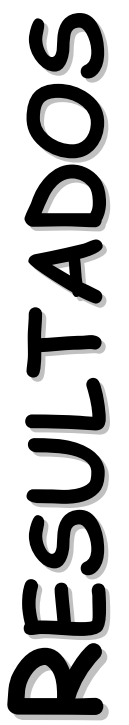




\section{RESULtAdOS}

\subsection{MiCROfLUORESCÊNCIA DE RAIOS-X POR ENERGIA DISPERSIVA ( $\mu$ EDX)}

$\mathrm{Na}$ análise química observou-se não haver diferença estatisticamente significativa na porcentagem em peso de íons cálcio $(\mathrm{Ca})$, fósforo $(\mathrm{P})$ e na relação $\mathrm{Ca} / \mathrm{P}$ entre o esmalte de dentes permanentes e o de dentes decíduos $(p>0,05)$. Os valores médios e os desviospadrão obtidos para cada substrato estão apresentados na Tabela 1 e as imagens obtidas e analisadas pelo equipamento estão apresentadas na Figura 8 (A e B).

TABela 1 - Médias (\%) e desvios-padrão de cálcio (Ca) e fósforo $(P)$ e proporção $\mathrm{Ca} / \mathrm{P}$, em peso $(\%)$

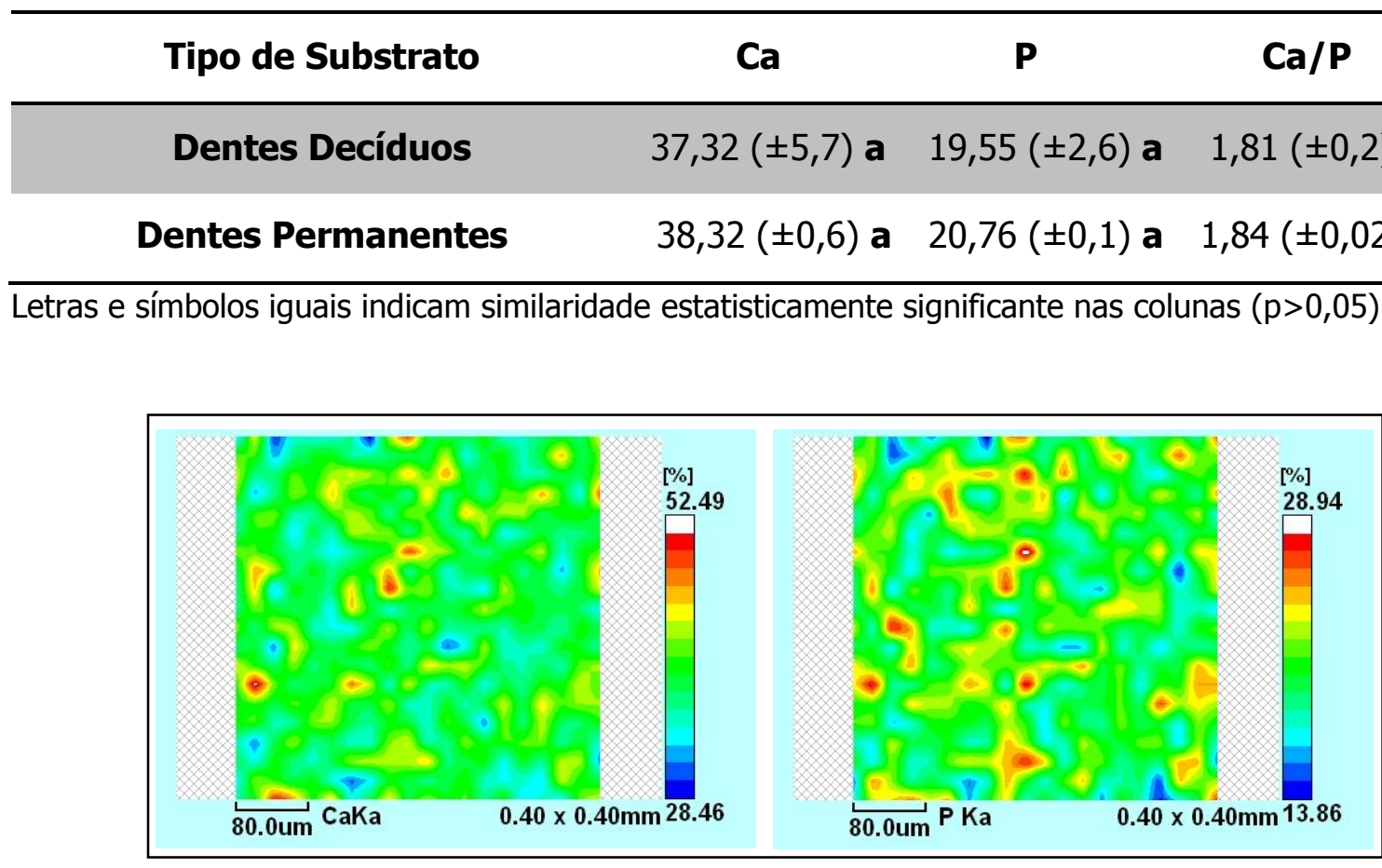

Figura 8A Amostra do esmalte de dente decíduo analisado, demonstrando os valores (máximo e mínimo) da concentração em peso (\%) dos íons Cálcio (Ca) e Fósforo (P).

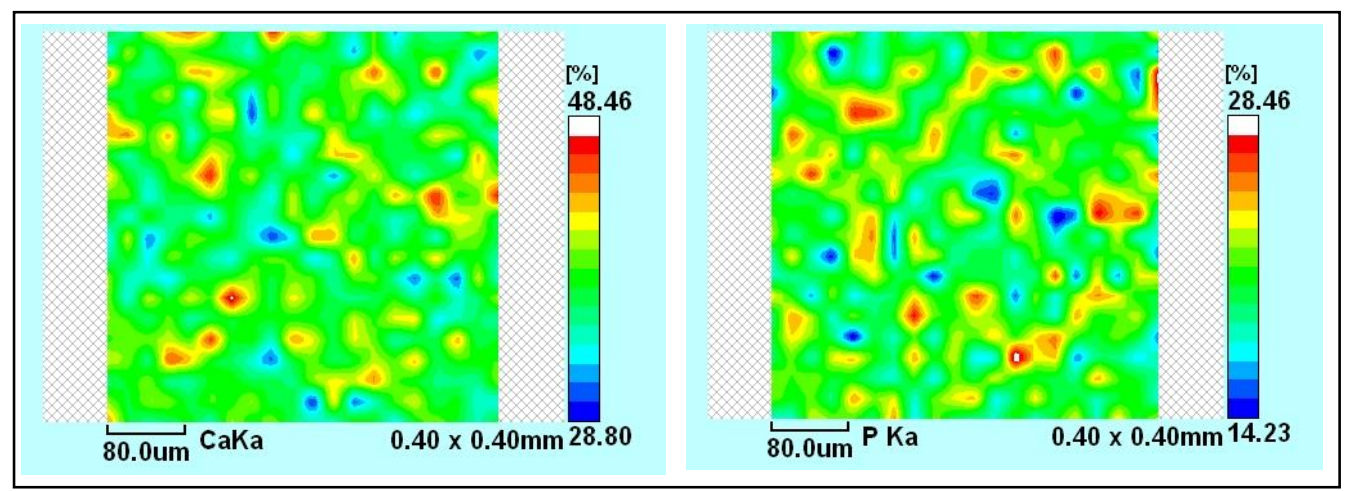

FiguRA 8B Amostra do esmalte de dente permanente analisado, demonstrando os valores (máximo e mínimo) da concentração em peso (\%) dos íons Cálcio (Ca) e Fósforo $(\mathrm{P})$. 


\subsection{ESPECTROSCOPIA NO INFRAVERMELHO POR TRANSFORMADA DE FOURIER (FTIR)}

$\mathrm{Na}$ análise dos dados obtidos, não foram observadas diferenças significativas para os valores de médios das bandas de $\mathrm{CO}_{3}{ }^{2}$ (carbonato) e água entre o esmalte de dentes decíduos e permanentes ( $p>0,05$ ). Os valores médios (obtidos em unidades arbitrárias) e os desvios-padrão das áreas dos espectros do esmalte de dentes decíduos e permanentes estão descritos na Tabela 2 e nas Figuras 9 e 10.

TABela 2 - Valores médios (u.a.) e desvios-padrão de carbonato e água presente nos substratos analisados

\begin{tabular}{ccc}
\hline Tipo de Substrato & $\mathbf{C O}_{\mathbf{3}}{ }^{\mathbf{2}}$ & Água \\
\hline Dentes Decíduos & $0,078( \pm 0,013) \mathrm{a}$ & $0,112( \pm 0,019) \mathrm{A}$ \\
Dentes Permanentes & $0,090( \pm 0,013) \mathrm{a}$ & $0,121( \pm 0,024) \mathrm{A}$ \\
\hline
\end{tabular}

Letras e símbolos iguais indicam similaridade estatisticamente significante nas colunas $(p>0,05)$. 


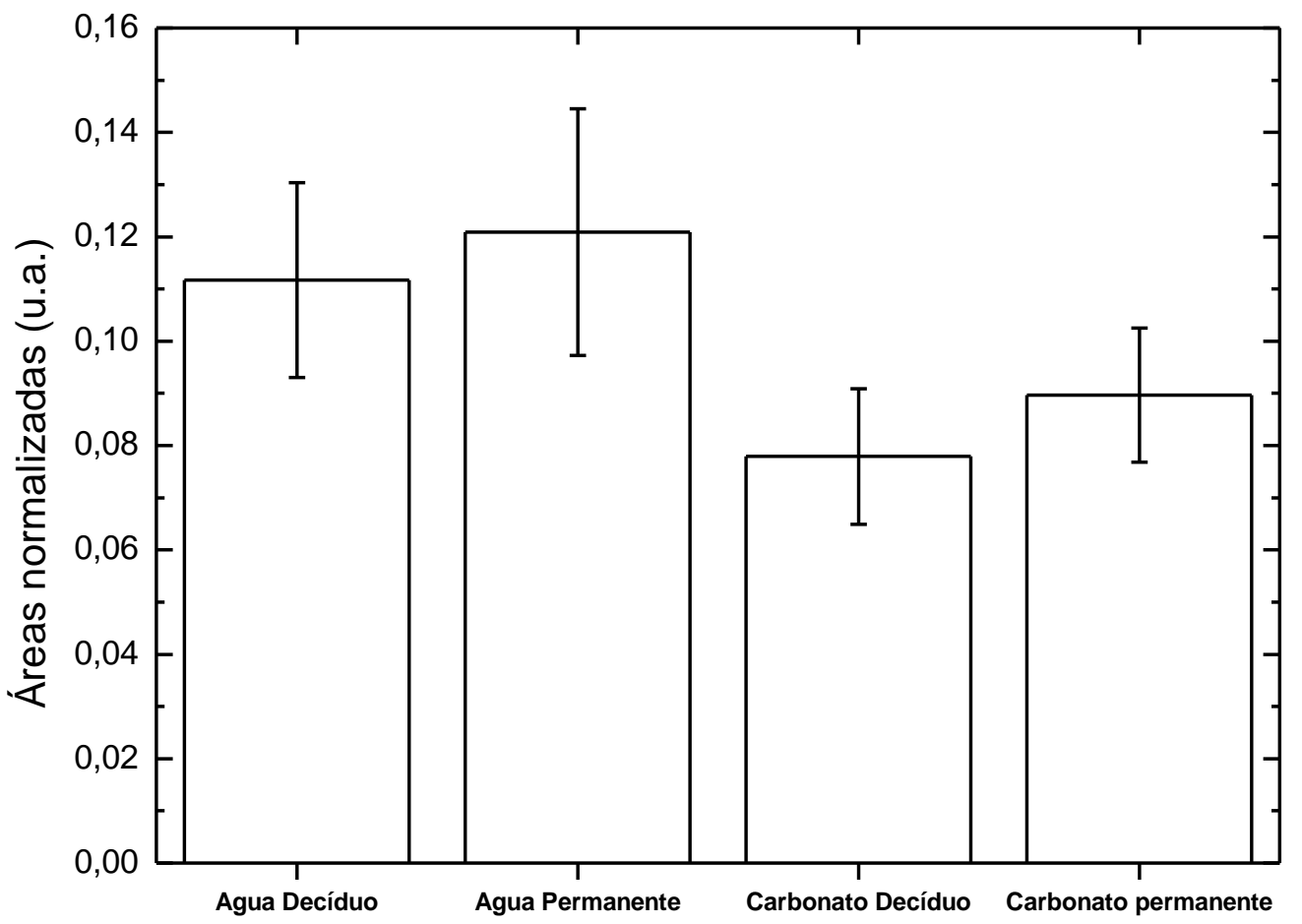

Figura 9 - Valores médios (u.a.) e desvios-padrão dos dados obtidos na análise de Espectroscopia no Infravermelho por Transformada de Fourier.

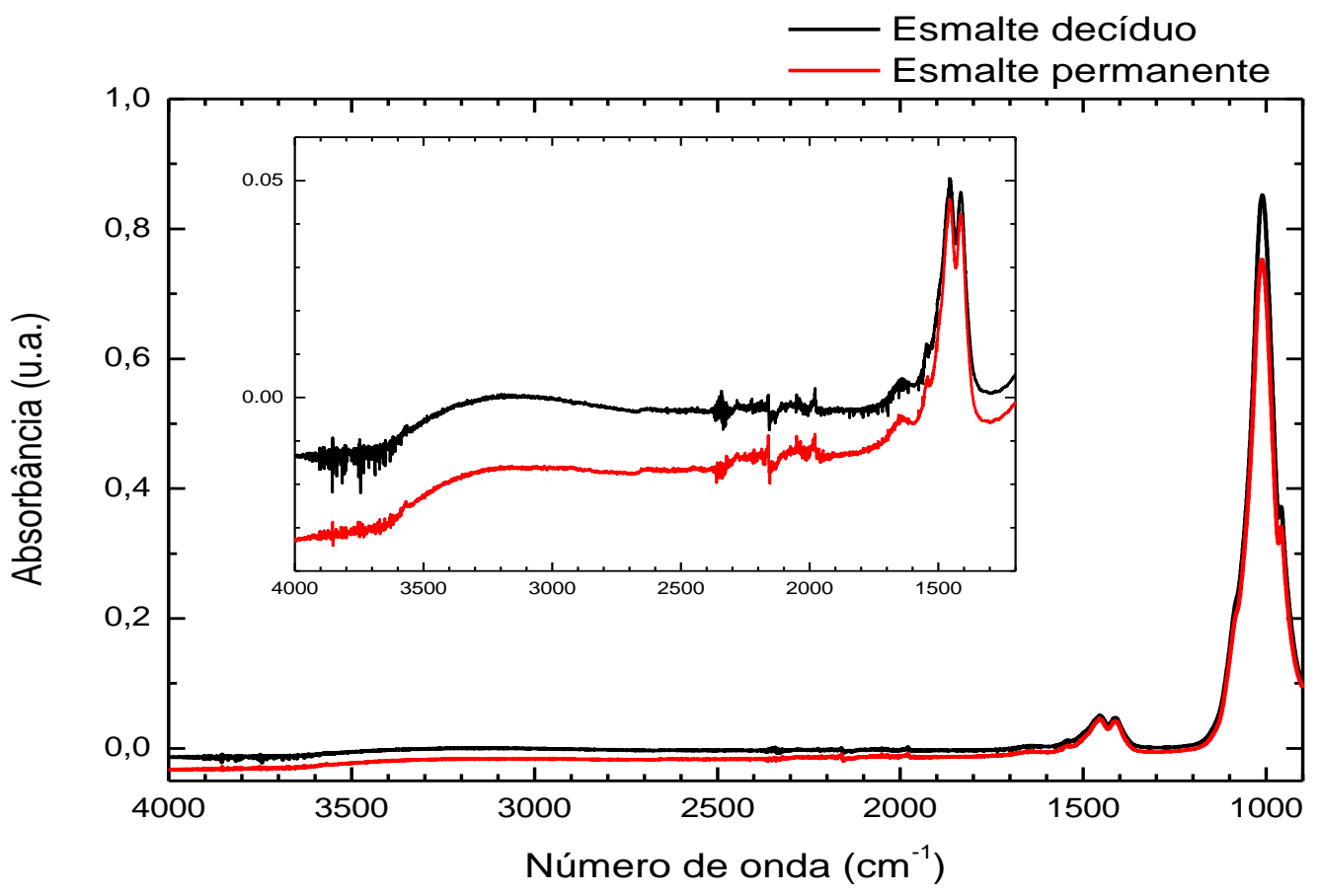

FIGURA 10 - Relação entre as médias dos espectros do esmalte de dentes decíduos (linha preta) e dentes permanentes (linha vermelha). 


\subsection{Permeabilidade}

$\mathrm{Na}$ permeabilidade pode-se observar diferença estatisticamente significante entre o esmalte de dentes decíduos e permanentes $(p<0,05)$, sendo que o esmalte dos dentes decíduos apresentou-se mais permeável que o esmalte dos dentes permanentes (Figura 11). Os valores médios e os desvios-padrão obtidos para cada substrato estão apresentados na Tabela 3.

TABELA 3 - Médias (\%) e desvios-padrão do percentual de penetração do agente traçador nos diferentes substratos

Tipo de Substrato

Dentes Decíduos

Dentes Permanentes

\section{Permeabilidade (\%)}

$$
36,93( \pm 10,11) \mathbf{a}
$$

$$
8,04( \pm 5,52) \mathbf{b}
$$

Letras diferentes indicam diferença estatisticamente significante $(p<0,05)$.

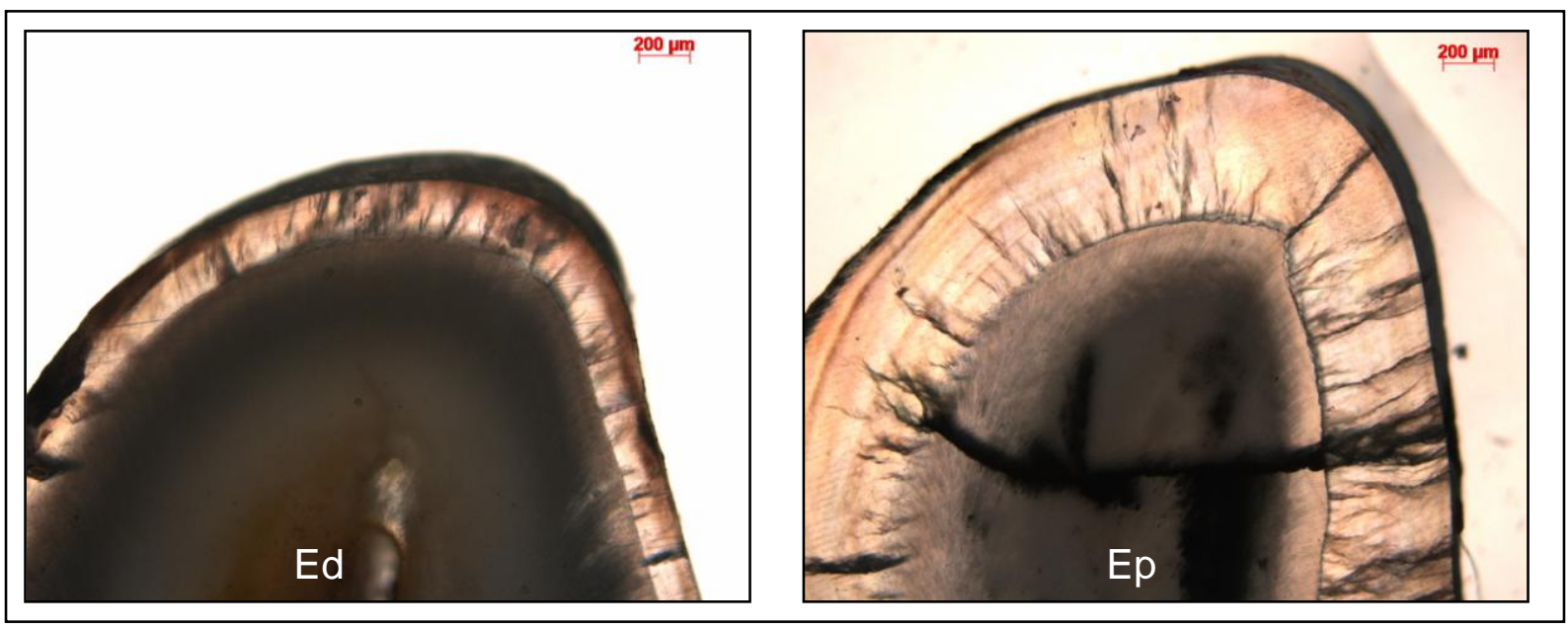

Figura 11 Imagens do esmalte de dente decíduo (Ed) e de dente permanente (Ep), demonstrando a penetração do agente traçador. 


\subsection{MicROdUREZA}

$\mathrm{Na}$ análise dos dados de Microdureza Knoop observou-se haver diferença estatisticamente significante entre o esmalte de dentes decíduos e permanentes $(p<0,05)$, sendo que os maiores valores de dureza foram obtidos no esmalte de dentes permanentes. Os valores médios e os desvios-padrão obtidos para cada substrato estão apresentados na Tabela 4.

TABELA 4 - Médias (KHN) e desvios-padrão dos substratos testados

\begin{tabular}{cc}
\hline Tipo de Substrato & Microdureza \\
\hline Dentes Decíduos & $292,63( \pm 22,2) \mathbf{a}$ \\
Dentes Permanentes & $358,33( \pm 37,1) \mathbf{b}$ \\
\hline
\end{tabular}

Letras diferentes indicam diferença estatisticamente significante $(p<0,05)$.

\subsection{RADIODENSIDADE}

Em relação à Radiodensidade do esmalte observou-se que houve diferença estatisticamente significativa entre os substratos $(p<0,05)$. Pode-se observar na análise dos dados que os valores de densidade óptica do esmalte de dentes decíduos foram estatisticamente superiores aos valores obtidos no esmalte de dentes permanentes. Os valores médios e os desvios-padrão obtidos para cada substrato estão apresentados na Tabela 5.

TABELA 5 - Médias e desvios-padrão da Radiodensidade (u.a) dos diferentes substratos

\begin{tabular}{cc}
\hline Tipo de Substrato & Densidade Óptica \\
\hline Dentes Decíduos & $1,61( \pm 0,05) \mathbf{a}$ \\
Dentes Permanentes & $1,56( \pm 0,04) \mathbf{b}$ \\
\hline
\end{tabular}

Letras diferentes indicam diferença estatisticamente significante $(p=0,008)$. 


\subsection{ResistênCIA Coesiva (Ultimate Tensile StRENGTH)}

$\mathrm{Na}$ análise dos dados, observou-se que houve diferença estatisticamente significante $(p<0,05)$ entre os substratos, sendo que o esmalte do dente decíduo apresentou valores inferiores ao dente permanente. Em relação à direção dos prismas, observou-se diferença estatística significante $(p<0,05)$ entre as regiões, tendo a disposição perpendicular apresentado valores inferiores à disposição paralela. Os valores médios e os desvios-padrão obtidos para cada substrato estão apresentados na Tabela 6.

TABela 6 - Médias (MPa) e desvios-padrão da resistência Coesiva dos diferentes substratos/disposição dos prismas

\begin{tabular}{ccc}
\hline Tipo de Substrato & \multicolumn{2}{c}{ Resistência Coesiva } \\
& Perpendicularmente & Paralelamente \\
\hline Dentes Decíduos & $20,75( \pm 4,08) \mathrm{b}$ & $31,48( \pm 6,43) \mathrm{B}$ \\
Dentes Permanentes & $22,13( \pm .5,12) \mathrm{a}$ & $37,41( \pm 7,04) \mathrm{A}$ \\
\hline
\end{tabular}

Letras diferentes indicam diferença estatisticamente significante nas colunas $(p<0,05)$. 



\section{DISCUSSÃo}

\subsection{Microfluorescência de Raios-X POR Energia Dispersiva ( $\mu$ EDX) E ESPECTROSCOPIA NO INFRAVERMELHO POR TRANSFORMADA DE FOURIER (FTIR)}

As técnicas de $\mu$ EDX e FTIR constituem ferramentas úteis que permitem, respectivamente, uma análise qualitativa e quantitativa dos elementos presentes na amostra e a determinação da composição química molecular dos substratos.

A determinação da composição química dos tecidos dentários é importante, visto que a qualidade do substrato influenciará a determinação dos protocolos restauradores e preventivos adequados. Na presente investigação o esmalte de dente decíduo apresentou composição química similar em comparação ao esmalte de dente permanente.

Em relação ao conteúdo de cálcio e fósforo o presente estudo apresentou resultados similares a outros trabalhos (Naujoks et al., 1967; Lakoma e Rytomaa, 1977), que não observaram diferenças entre esmalte de dentes decíduos e permanentes. Os valores médios observados para o cálcio e o fósforo, no esmalte de dentes permanentes foram semelhantes aos observados por Derise et al. (1974). Com relação ao dente decíduo Le Geros et al. (1985) relataram uma porcentagem de 1,61 da relação $\mathrm{Ca} / \mathrm{P}$, valor inferior ao observado no presente estudo $(1,81)$.

Ao contrário dos achados deste estudo, Søjun Clasen e Ruyter (1997) observaram maior conteúdo de carbonato no esmalte de dentes decíduos. Outros autores (Tagliafero et al., 2009; de Sant'Anna et al., 2009) também relataram valores superiores na quantidade de carbonato do esmalte de dentes decíduos, quando analisados utilizando espectroscopia Raman por transformada de Fourier.

Podem-se explicar estas diferenças em função da metodologia empregada, da procedência regional e étnica dos dentes estudados, do grupo de dentes analisados ou mesmo ao tempo de permanência do dente decíduo na cavidade bucal, pois todos esses fatores podem afetar a composição química das estruturas dentais. Alguns autores relatam que o conteúdo de cálcio pode aumentar (Derise et al., 1974) e que a solubilidade e o conteúdo de carbonato no esmalte podem diminuir com o aumento da idade dental (Brudevold, 1948; 1960; Sidney-Zax et al., 1991). 
O esmalte é composto basicamente por mineral (95\%), tendo a apatita como principal componente, esta é um fosfato de cálcio que possui estrutura hexagonal formada por um sítio tetraédrico $\left(\mathrm{PO}_{4}^{-3}\right)$ que está ligado ao cálcio em dois sítios estruturais diferentes. Ela é formada por um padrão definido de arranjo iônico que permite considerável variação na sua constituição por meio da substituição, troca e adsorção de íons. As variantes mais freqüentes de apatita são: hidroxiapatita $\left[\mathrm{Ca}_{10}\left(\mathrm{PO}_{4}\right)_{6} \mathrm{OH}_{2}\right]$ e fluorapatita $\left[\mathrm{Ca}_{10}\left(\mathrm{PO}_{4}\right)_{6} \mathrm{~F}_{2}\right](\mathrm{Ten}$ Cate, 2001).

Tais substituições podem acontecer de forma rápida ou lenta, dependendo de fatores como desgaste, difusão de íons, oxidação, decomposição e precipitação. Essas substituições podem alterar a cristalinidade, as dimensões dos cristais, a textura superficial, a estabilidade e a solubilidade da estrutura da hidroxiapatita. O cálcio pode ser substituído pelo magnésio e pelo sódio; fluoretos e cloretos podem ocupar a posição da hidroxila; o carbonato pode ocupar tanto a posição da hidroxila (tipo A) quanto do fosfato (tipo B). Além disso, embora a estrutura da hidroxiapatita seja preservada, as alterações químicas e estruturais que acompanham tais substituições podem afetar as propriedades físicas e químicas do esmalte (Reitznerova et al., 2000, Leventouri et al., 2009). Portanto, a avaliação de outros íons e moléculas, bem como do conteúdo inorgânico, por meio de técnicas mais específicas se faz necessária para uma efetiva comparação entre estes substratos

\subsection{Permeabilidade}

A metodologia histoquímica empregada na análise da Permeabilidade foi originalmente descrita para o tecido dentinário (Pécora et al., 1991). Porém, estudos prévios realizaram a adaptação da metodologia para avaliação da permeabilidade em esmalte (Schiavoni et al., 2006; Turssi et al., 2006) e, posteriormente, para a análise em esmalte de dentes decíduos (Azevedo, 2011).

A análise da permeabilidade constitui-se um método eficaz para a avaliação de procedimentos preventivos e das alterações dos tecidos dentários frente aos procedimentos restauradores (Turssi et al., 2006; Chersoni et al., 2011).

A maioria dos estudos é realizada somente em dentes permanentes, ou somente em dentes decíduos. Entretanto, dentes decíduos e permanentes possuem características 
próprias que podem influenciar na permeabilidade dos tecidos, e devem ser comparados utilizando os mesmos métodos, como no presente estudo.

No presente trabalho observou-se que o esmalte de dentes decíduos mostrou-se mais permeável em comparação ao esmalte de dentes permanentes. Resultados semelhantes foram relatados por Linden et al. (1986), os quais observaram que o coeficiente de difusão médio do EDTA (ácido etilenodiaminotetracético) e da clorexidina foi cerca de 30 vezes enquanto o de flúor foi 150 vezes maior no esmalte de dente decíduo comparativamente ao de dente permanente. Possivelmente, a maior densidade e menor diâmetro dos prismas (Oliveira et al., 2010) e maior área de esmalte interprismático e densidade das junções entre os prismas no esmalte de dentes decíduos (Shellis, 1984a) explicariam estes resultados.

Adicionalmente, a menor organização dos cristais de hidroxiapatita (Cevc et al., 1980) no esmalte do dente decíduo resultariam em um tecido com maior porosidade e permeabilidade (Mortimer, 1970). Fato este verificado por Silverstone (1970), que relatou uma porcentagem de poros no esmalte do dente decíduo variando de $1-5 \%$ nas regiões mais internas do tecido, em comparação a porcentagem de 0,1 a $0,2 \%$ observada nos dentes permanentes.

O conteúdo orgânico no esmalte está presente em concentrações muito baixas (1\%), sob a forma de pequenos peptídeos e aminoácidos distribuídos pelo tecido como remanescentes da matriz orgânica sintetizada na fase de desenvolvimento do substrato, provavelmente ligados aos cristais de hidroxiapatita. Na região interprismática existe menor densidade de cristais e, portanto, maior conteúdo orgânico. Esta fase protéica associada à presença da água (4\%) permite a difusão de substâncias, conferindo a propriedade de permeabilidade deste substrato (Brik et al., 2000).

Desta forma, sabendo-se que na presente pesquisa não se observou diferença na composição química entre os substratos, pode-se relacionar a maior permeabilidade a uma maior área de regiões interprismática e intercristalina no esmalte de dentes decíduos.

Aliando-se a estes dados, o fato da espessura do esmalte do dente decíduo ser a metade da espessura do dente permanente (Mortimer, 1970; Oliveira et al., 2010), a maior permeabilidade do esmalte do dente decíduo comparativamente a do dente permanente seria mais preocupante. Isto porque a espessura do tecido é um dos fatores importantes contra injúrias patológicas e iatrogênicas, pois esta age como uma barreira contra agressões do meio bucal. 
Estes resultados poderiam explicar a maior suscetibilidade do esmalte do dente decíduo frente aos desafios ácidos observada na literatura. Mejàre e Stenlund (2000) relataram que a incidência de lesões cariosas no esmalte de dentes permanentes foi de 4,6 lesões/100 superfícies dentárias ao ano em comparação à taxa de 11,3 lesões para o esmalte de dentes decíduos, concordando com os dados de outros estudos (Featherstone e Mellberg, 1981; Shellis, 1984b).

Logo, a maior permeabilidade do esmalte do dente decíduo indica a necessidade de protocolos preventivos e restauradores específicos para este substrato.

\subsection{MiCRODUREZA}

A microdureza é definida com a mensuração da resistência à deformação permanente de uma superfície quando uma carga é aplicada por um endentador (aço, tungstênio ou diamante). A medida da dureza se dá pela relação entre unidade de força pela unidade de área deformada. A Microdureza Knoop, aplicada neste estudo, tem sido amplamente utilizada nos substratos dentários, pois sua endentação permite medidas mais precisas mesmo em áreas onde as marcas são rasas, devido ao fato de sua ponta de penetração possuir uma diagonal longa (Kinney et al., 2003). Ainda, esta pode estar relacionada com outras propriedades mecânicas como resistência à fratura, módulo de elasticidade e força de adesão (Cuy et al., 2002; Kinney et al., 2003).

Na presente investigação os valores de microdureza Knoop foram maiores no esmalte de dentes permanentes comparativamente aos dentes decíduos, concordando com os resultados de outros estudos (Lussi et al., 2000; Correr et al., 2007; Low et al., 2008). Ainda, estes valores são semelhantes aos encontrados na literatura para o esmalte de dentes decíduos e permanentes, quando analisados isoladamente (Argenta et al., 2003; Torres et al., 2010).

O conteúdo mineral do esmalte pode afetar os valores de dureza (Cuy et al., 2002; Braly et al., 2007; Jeng et al., 2011), entretanto pequenas alterações nos conteúdos mineral e orgânico do esmalte não foram correlacionadas com os achados de dureza (Kodaka et al. 1992). Variações nas propriedades mecânicas podem ser atribuídas a outros fatores, como diferenças na cristalografia (densidade e orientação dos cristais) (Habelitz et al., 2001; He at al., 2010). 
Neste contexto, autores observaram que o esmalte dos dentes decíduos apresentam maior número e menor diâmetro dos prismas em relação aos permanentes (Oliveira et al., 2010), além de observaram uma menor organização dos cristais de hidroxiapatita (Cevc et al. 1980), características que poderiam afetar negativamente a dureza do esmalte de dente decíduo. Low et al. $(2006 ; 2008)$ correlacionaram os menores valores de dureza observados no esmalte de dentes decíduos em comparação a dentes permanentes à presença de cristais mais grosseiros nos dentes decíduos e afirmaram que as propriedades mecânicas dos tecidos dentários estariam relacionadas não somente às diferenças estruturais, mas também à umidade presente no substrato. Zheng e Zhou (2005) demonstraram que dentes permanentes tiveram maior resistência ao desgaste que dentes decíduos e atribuíram os achados, em parte, à maior dureza e ao alinhamento mais perpendicular dos prismas na superfície oclusal do esmalte.

Alguns autores (Roy e Basu, 2008; He e Swain, 2009) atribuíram a diminuição das propriedades mecânicas (módulo de elasticidade e dureza) do esmalte da superfície à junção amelo-dentinária às características microestruturais locais no tecido como a orientação dos prismas e organização dos cristais. Habelitz et al. (2001) confirmaram este fato ao reportar que os valores do módulo de elasticidade e a dureza são menores na cauda dos prismas em relação à cabeça, devido a diferenças na orientação dos cristais de hidroxiapatita.

O padrão de orientação dos prismas de esmalte pode ser atribuído ao vetor de movimento dos ameloblastos durante a síntese da matriz proteica, que também pode influenciar a orientação dos cristais do esmalte (Smith, 1998).

Desta forma, considerando que os dentes decíduos apresentam maior velocidade de formação e mineralização e menor ciclo de vitalidade nos tecidos (Shellis, 1984a, Araújo et al., 1995), mesmo que o esmalte do dente decíduo tenha apresentado valores da composição química similares ao dente permanente, os resultados em relação à microdureza Knoop poderiam ser explicados por uma possível diferença no arranjo microestrutural destes substratos.

As propriedades mecânicas do esmalte de dente decíduo comparativamente ao dente permanente são pouco estudadas. A determinação e comparação destas propriedades sob as mesmas condições de preparo e teste é importante, visto que o conhecimento destas características esclareceria o comportamento destes substratos sob condições clínicas. 


\subsection{RADIODENSIDADE}

Um dos objetivos principais da Odontologia é a promoção e manutenção da saúde bucal. Para tal finalidade, o correto diagnóstico da doença cárie e o controle preciso da utilização dos materiais capeadores, forradores e restauradores se tornam mandatórios. Neste sentido, um importante método auxiliar é a utilização da imagem radiográfica. Os materiais odontológicos deveriam apresentar-se radiograficamente com tonalidades das nuances que permitissem diferenciá-los das estruturas anatômicas adjacentes e de lesões de cárie (Espelid et al., 1991; Hara et al., 2001).

A radiopacidade é uma propriedade importante dos materiais odontológicos e tecidos biológicos mineralizados e pode ser definida como o inverso da densidade óptica da imagem radiográfica. A densidade radiográfica pode ser descrita como o grau de enegrecimento da radiografia concluída. Quanto maior o grau de escurecimento, maior a densidade e menor a quantidade de luz que atravessará a radiografia quando colocada na frente de um negatoscópio ou de um foco de luz (Souza et al., 2010).

A densidade óptica é o logarítimo da razão da intensidade de luz incidente pela intensidade de luz transmitida por meio do filme radiográfico. Esta não depende somente da metodologia usada como tipo de filme, parâmetros de exposição e processamento radiográficos, mas também, das propriedades de absorção de radiação do próprio substrato (Watts e McCabe, 1999).

Desta maneira, no presente estudo objetivou-se padronizar as outras variáveis que poderiam interferir na densidade óptica. Assim, as diferenças existentes seriam resultantes apenas das características químicas e microestruturais de cada tecido avaliado.

A radiodensidade de uma imagem radiográfica será influenciada pela composição atômica e molecular do tecido e dos materiais, bem como de sua estrutura física e espessura (Fonseca et al., 2004). Para assegurar um contraste adequado da radiografia, os espécimes utilizados apresentaram um espessura de $2 \mathrm{~mm}$ (Watts e McCabe, 1999). Este fator é importante para um diagnóstico diferencial, porque com uma espessura menor provavelmente não seria possível distinguir as três estruturas dentárias mineralizadas na imagem radiográfica (esmalte/dentina/cemento), uma vez que estes espécimes não apresentariam espessura suficiente para impedir a passagem os raios- $X$ e assim formar a imagem radiográfica no filme. 
A metodologia utilizada nesta investigação foi similar a de outros estudos que avaliaram a radiopacidade de materiais (Devito et al., 2004; Souza et al., 2010; Aguilar et al., 2011).

As diretrizes da Organização Internacional para Padronização - 4049 (1985) determinam que um material odontológico resinoso deva apresentar uma radiopacidade no mínimo igual a do alumínio puro, na mesma espessura que é aproximadamente a radiopacidade da dentina do dente permanente (van Dijken et al., 1989). No entanto, alguns autores concluíram que para um ótimo contraste um material restaurador que apresentasse uma radiopacidade ligeiramente maior ou igual a do esmalte do dente permanente seria ideal para o diagnóstico correto de lesões de cárie nas radiografias, bem como para a avaliação dos materiais odontológicos (Espelid et al., 1991; Chan et al., 1999). Isto porque uma radiopacidade muito maior que a do esmalte também poderia interferir na detecção de alterações e na diferenciação dos materiais em relação às estruturas anatômicas adjacentes (Devito et al., 2004).

No presente estudo, o esmalte do dente permanente apresentou menores valores de radiodensidade em comparação ao esmalte do dente decíduo, ou seja, o esmalte do dente permanente mostrou-se mais radiopaco que o do dente decíduo. $\mathrm{O}$ valor médio da densidade óptica do esmalte de dentes permanentes foi semelhante ao reportado por Souza et al. (2010) $(1,46)$ e por Devito et al. (2004) $(1,56)$, utilizando a mesma metodologia.

Wilson e Beynon (1989) avaliaram o esmalte de dentes decíduos e permanentes por meio da microradiografia e observaram que o dente decíduo apresentou menor grau de mineralização. Na presente investigação, apesar da semelhança na análise química, os valores de microdureza foram diferentes para os substratos comparados, sugerindo uma diferença na estrutura física entre o esmalte do dente decíduo e do dente permanente, o que poderia explicar os valores de radiodensidade obtidos.

Neste contexto, Oliveira et al. (2010) observaram que o esmalte de dentes decíduos apresentou maior número de prismas em relação aos dentes permanentes. Low et al. (2006; 2008) observaram que os cristais são mais irregulares e maiores (185 nm) no esmalte de dentes decíduos em comparação ao dente permanente $(94 \mathrm{~nm}$ ). Além disso, o esmalte de dentes decíduos apresenta maior porosidade em relação ao dente permanente (Silverstone, 1970).

Os resultados observados no presente estudo indicam uma maior dificuldade de se realizar um diagnóstico precoce de alterações no esmalte de dente decíduo, importante neste tecido uma vez que suas características e propriedades favorecerem a progressão de lesões de cárie. 
O questionamento sobre o quão radiopaco um material deveria apresentar-se para um correto e preciso diagnóstico tem sido avaliado por vários autores (Devito et al., 2004; Ergücü et al., 2010). Como descrito, os materiais odontológicos são fabricados e avaliados no que diz respeito à radiopacidade em comparação com as estruturas de dentes permanentes ou ao alumínio. No entanto, não se tem o conhecimento de artigos que investigaram a radiopacidade dos materiais odontológicos em comparação com as estruturas dentárias de dentes decíduos. Sabendo-se que as características dos substratos interferem nos valores de densidade óptica e que a literatura específica evidencia diferenças morfológicas na composição química e estrutural entre dentes decíduos e dentes permanentes, justifica-se o conhecimento dos valores de densidade óptica do esmalte de dente decíduo para que sejam desenvolvidos materiais e protocolos preventivos específicos para este tecido, visando um correto diagnóstico de alterações na cavidade bucal.

\subsection{Resistência Coesiva (Ultimate tensile Strength)}

Para minimizar o desgaste dentário funcional na cavidade bucal, o dente é constituído por tecidos mineralizados que apresentam propriedades físicas baseadas em sua composição e estrutura micromorfológica. No esmalte a resistência a tração é anisotrópica e se relaciona com o tipo e direção da força aplicada, bem como com a densidade e orientação das estruturas no tecido, cristais de hidroxiapatita e prismas (Xu et al., 1998; Gianinni et al., 2004). Esta estrutura anisotrópica dos cristais nos prismas desempenha uma importante função na biomecânica do esmalte para resistir e dissipar as forças mastigatórias e os impactos na cavidade bucal, uma vez que o esmalte apresenta baixa resistência à tração (Spears et al., 1993; Roy e Basu, 2008).

Nas restaurações adesivas, principalmente, o selamento e a integridade das margens são muito importantes para o sucesso clínico. A resistência adesiva dos sistemas adesivos atuais geralmente é avaliada em superfícies planificadas do esmalte dental, onde os prismas estão dispostos perpendicularmente à superfície de teste. No entanto, nas margens dos preparos cavitários, os prismas encontram-se dispostos paralelamente à superfície adesiva. Portanto, o conhecimento da resistência à tração dos tecidos que compõem a estrutura dental variando a orientação da força aplicada é importante para que protocolos e materiais específicos para cada substrato sejam instituídos. Neste contexto, Han et al. (1990) enfatizaram a importância do biselamento das margens do preparo cavitário e do polimento 
tardio das restaurações, para manter a integridade e melhorar o selamento marginal. Os trabalhos publicados, em sua maioria, utilizaram dentes permanentes e não foram encontrados autores que tenham comparado o esmalte de dentes decíduos e permanentes em um mesmo trabalho.

Desde sua introdução (Sano et al., 1994), o ensaio de microtração tem sido amplamente utilizado para a análise da resistência mecânica da interface adesiva entre os materiais odontológicos e as estruturas dentárias, bem como para a análise da resistência à tração do próprio tecido e dos materiais (Giannini et al., 2004; Lührs et al., 2011). As maiores vantagens do teste de microtração são a maior uniformidade da distribuição das tensões na área de teste e a possibilidade de avaliar a resistência mecânica em áreas menores com maior fidelidade dos valores obtidos (Pashley et al., 1995; Pashley et al., 1999).

$\mathrm{Na}$ presente investigação o esmalte do dente decíduo apresentou valores de resistência coesiva inferiores aos obtidos no esmalte do dente permanente. Em relação à direção dos prismas, quando a força de tração foi aplicada perpendicularmente à disposição dos prismas os valores foram inferiores nos dois substratos, quando analisados isoladamente. Resultados semelhantes foram observados em outros estudos em relação à orientação da força aplicada (Carvalho et al., 2000; Ikeda et al., 2002; Gianinni et al., 2004).

Quando a força é aplicada perpendicularmente à orientação dos prismas do esmalte, a região interprismática rapidamente propaga a tensão pelo tecido ocasionando a fratura, separando os prismas. Poucos prismas são clivados em regiões onde os prismas alteram a orientação. Ao contrário, quando a força é aplicada paralelamente a orientação dos prismas, a tensão se concentra no corpo dos prismas, sendo necessária uma força maior para a ruptura destas estruturas, ocasionando a fratura do tecido (Gianinni et al., 2004). A orientação dos cristais no tecido também influencia na resistência à tração do substrato, pois apesar dos cristais não serem clivados durante a fratura, eles apresentam menor densidade e maior desorganização na região interprismática (Stephene et al., 1976), necessitando uma força menor para a ruptura do tecido, quando esta é aplicada perpendicularmente à orientação prismática.

Os valores observados na presente investigação foram de aproximadamente 22,13 MPa aplicando a força perpendicularmente à direção dos prismas e de 37,41 MPa aplicando a força paralelamente à direção dos prismas do esmalte do dente permanente. Resultados semelhante foram observados por Gianinni et al. (2006) que observaram valores de 36,4 MPa quando avaliando o esmalte de dentes permanentes na direção paralela aos prismas. 
Gianinni et al. (2004) descreveram valor médio de 42,1 MPa analisando o esmalte de dentes permanentes aplicando a força paralelamente à direção dos prismas e de 11,5 MPa aplicando a força perpendicularmente à direção dos prismas. Não se tem conhecimento de trabalhos na literatura avaliando a resistência coesiva do esmalte do dente decíduo.

Diante dos resultados deste trabalho, pode-se atribuir a menor resistência à tração do esmalte do dente decíduo às diferenças nas características microestruturais dos tecidos analisados, como disposição e densidade dos prismas e cristais. Visto que no dente decíduo a velocidade de síntese e maturação dos tecidos é maior e a espessura é menor (Mortimer, 1970; Shellis, 1984a; Araújo et al., 1995; Oliveira et al., 2010), os cristais de hidroxiapatita seria menos organizados nos dentes decíduos, como observado por Cevc et al. (1980). Estudos mais específicos em relação à cristalografia comparativamente entre o esmalte de dentes decíduos e permanentes são necessários.

O conhecimento da resistência coesiva do esmalte é importante na definição dos limites de resistência adesiva e no desenvolvimento dos protocolos e materiais restauradores, para que não ocorram fraturas coesivas no substrato, bem como de técnicas de preparo das cavidades, como o biselamento das margens, específicos para cada substrato. Ainda, esta propriedade determina os limites e áreas de ocorrência de fratura em cada tecido, que podem implicar em hipersensibilidade, suscetibilidade às lesões de desmineralização e até à pulpite.

Estudos comparativos do esmalte de dentes decíduos e permanentes quanto à análise das propriedades químicas e físicas são escassos. Esse fato, aliado às diferenças nas metodologias empregadas nos estudos, definiu-se como um obstáculo e um desafio para que os resultados da presente investigação pudessem ser comparados aos da literatura consultada. Algumas peculiaridades próprias do esmalte do dente decíduo, observadas no presente trabalho, sugerem possíveis condutas clínicas distintas daquelas adotadas nos dentes permanentes. Em face disso, outros estudos se fazem necessários para o entendimento mais preciso da estrutura do dente decíduo, fornecendo maior embasamento para a conduta clínica, que assim terá o respaldo biológico necessário. 


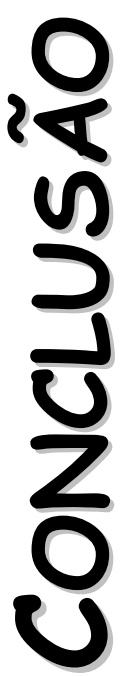




\section{CONCLUSÃo}

Considerando-se as limitações de um estudo in vitro, pode-se concluir que:

- Para as propriedades químicas avaliadas, constatou-se que o conteúdo em peso de cálcio (\%), fósforo (\%), da proporção $\mathrm{Ca} / \mathrm{P}(\%)$, bem como os conteúdos de fosfato, carbonato e água, foram semelhantes entre os dois substratos avaliados.

- Em relação às propriedades físicas, o esmalte de dentes decíduos apresentou maior permeabilidade, maior radiodensidade, menor resistência coesiva e menor microdureza do substrato quando comparado ao esmalte de dentes permanentes. 


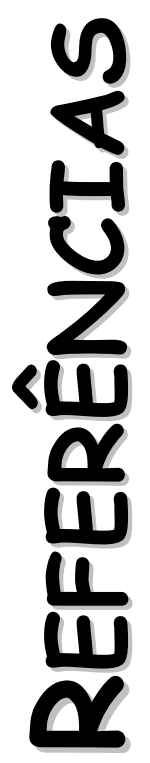




\section{REFERÊNCIAS}

Aguilar FG, Garcia LFR, Rossetto HL, Pardini LC, Pires-de-Souza FCP. Radiopacity evaluation of calcium aluminate cement containing different radiopacifying agents. J Endod 2011;37:6771.

Amaechi BT, Higham SM, Edgar WM. Factors influencing the development of dental erosion in vitro: enamel type, temperature and exposure time. J Oral Rehabil 1999;26:624-30.

Araújo FB, Moraes FF, Fossati ACM. A estrutura da dentina do dente decíduo e sua importância clínica. Rev Bras Odont 1995;52:37-43.

Argenta RMO, Tabchoury CPM, Cury JA. A modified pH-cycling model to evaluate fluoride effect on enamel demineralization. Pes Odontol Bras 2003;17:241-6.

Azevedo DT. Avaliação in vitro da resistência ácida e da permeabilidade do esmalte dental decíduo irradiado com laser Nd:YAG associado ou não ao flúor [dissertação]. Ribeirão Preto: Faculdade de Odontologia de Ribeirão Preto da Universidade de São Paulo; 2011.

Braly A, Darnell LA, Manna AB, Teaford MF, Weihs TP. The effect of prism orientation on the indentation testing of human molar enamel. Archs Oral Biol 2007;52:856-60.

Brik A, Haskell E, Brik V, Scherbina O, Atamanenko O. Anisotropy effects of EPR signals and mechanisms of mass transfer in tooth enamel and bones. Appl Radiat Isot 2000;52:1077-83.

Brudevold F, Steadman LT, Smith FA. Inorganic and organic components of tooth structure. Ann N Y Acad Sci 1960;29:110-32.

Brudevold F. A study of the phosphate solubility of the human enamel surface. J Dent Res $1948 ; 27: 320$.

Carlstrom D, Glas JE, Angmar B. Studies on the unltrastruture of dental enamel V. The state of water in human enamel. J Ultrastruct Res 1963;8:24-9.

Carvalho RM, Santiago SL, Fernandes CA, Suh BI, Pashley DH. Effects of prism orientation on tensile strength of enamel. J Adhes Dent 2000;2:251-7. 
Cevc G, Cevc P, Schara M, Skaleric U. The caries resistance of human teeth is determined by the spatial arrangement of hydroxyapatite microcrystals in the enamel. Nature $1980 ; 286: 425-6$.

Chan DCN, Titus HW, Chung KH, Dixon H, Wellinghoff ST, Rawls HR. Radiopacity of tantalum oxide nanoparticle filled resins. Dent Mater 1999;15:219-22.

Chersoni S, Bertacci A, Pashley DH, Tay FR, Montebugnoli L, Prati C. In vivo effects of fluoride on enamel permeability. Clin Oral Investig 2011;15:443-9.

Correr GM, Alonso RC, Consani S, Puppin-Rontani RM, Ferracane JL. In vitro wear of primary and permanent enamel. Simultaneous erosion and abrasion. Am J Dent 2007;20:394-9.

Cuy JL, Mann AB, Livi KJ, Teaford MF, Weihs TP. Nanoindentation mapping of the mechanical properties of human molar tooth enamel. Arch Oral Biol 2002;47:281-91.

da Costa CC, Oshima HM, Costa Filho LC. Evaluation of shear bond strength and interfacial micromorphology of direct restorations in primary and permanent teeth--an in vitro study. Gen Dent 2008;56:85-93

de Las Casas EB, Cornacchia TP, Gouvea PH, Cimini CA Jr. Abfraction and anisotropy--effects of prism orientation on stress distribution. Comput Methods Biomech Biomed Engin 2003;6:65-73.

de Sant'anna GR, Dos Santos EAP, Soares LES, Espírito-Santo AM, Martin AA, Duarte DA, Pacheco-Soares C, Brugnera Jr. A. Dental enamel irradiated with infrared diode laser and photoabsorbing cream: Part 1-FT-Raman Study. Photomed Laser Surg 2009;27:499-507.

Derise NL, Ritchey SJ, Furr AK. Mineral composition of normal human enamel and dentin and the relation of composition to dental caries I - Macrominerals. J Dent Res 1974;53:847-52.

Devito KL, Ortega AI, Haiter-Neto F. Radiopacity of calcium hydroxide cement compared with human tooth structure. J Appl Oral Sci 2004;12:290-3.

Eisenmann DR. Estrutura do Esmalte. In: Ten Cate, A. R. Histologia Bucal- Desenvolvimento, Estrutura e Função. Rio de Janeiro: Guanabara- Koogan; 2001. p. 205-221.

Ergücü $Z$, Türkün LS, Onem E, Güneri $P$. Comparative radiopacity of six flowable resin composites. Oper Dent 2010;35:436-40. 
Espelid I, Tveit AB, Erickson RL, Keck SC, Glasspoole EA. Radiopacity of restorations and detection of secondary caries. Dent Mater 1991;7:114-7.

Fava M, Watanabe I, Moraes FF, Costa LRRS. Prismless enamel in human non erupted deciduous molar teeth: a scanning eletron microscopic study. Rev Odontol Univ São Paulo 1997; 11:239-43.

Fava M, Watanabe I, Moraes FF. Fine structure and histometry of the enamel prismless layer of unerupted third molar teeth. Rev Chil Anat 1993;11:19-24.

Featherstone JD, Mellberg JR. Relative rates of progress of artificial carious lesions in bovine, ovine and human enamel. Caries Res 1981;15:109-14.

Fejerskov O, Josephsen K, Nyvad B. Surface ultrastructure of unerupted mature human enamel. Caries Res 1984;18:302-14.

Giannini M, Silva AP, Cavalli V, Leme AFP. Effect of carbamide peroxide-based bleaching agents containing fluoride or calcium on tensile strength of human enamel. J Appl Oral Sci $2006 ; 14: 82-7$

Giannini M, Soares CJ, de Carvalho RM. Ultimate tensile strength of tooth structures. Dent Mater 2004;20:322-9.

Gwinnett AJ. Normal enamel II. Qualitative polarized light study. J Dent Res. 1966;45:261-5.

Gwinnett AJ. Structure and composition of enamel. Oper Dent 1992;5:10-7.

Habelitz S, Marshall SJ, Marshall Jr GW, Balooch M. Mechanical properties of human dental enamel on the nanometre scale. Arch Oral Biol 2001;46:173-83.

Han L, Okamoto A, Iwaku M. The effect of various clinical factors on marginal enamel microcracks produced around composite restiration. Dent Mater J 1990;11:26-37.

Hara AT, Serra MC, Haiter-Neto F, Rodrigues AL Jr. Radiopacity of esthetic restorative materials compared with human tooth structure. Am J Dent 2001;14:383-6.

He B, Huang S, Jing J, Hao Y. Measurement of hydroxyapatite density and Knoop hardness in sound human enamel and a correlational analysis between them. Arch Oral Biol 2010;55:134-41. 
He LH, Swain MV. Enamel - A functionally graded natural coating. J Dent 2009;37:596-603.

Hunter ML, West NX, Hughes JA, Newcombe RG, Addy M. Erosion of deciduous and permanent dental hard tissue in the oral environment. J Dent 2000;28:257-263.

Ikeda T, Uno S, Tanaka T, Kawakami S, Komatsu H, Sano H. Relation of enamel prism orientation to microtensile bond strength. Am J Dent 2002;15:109-13.

International Standards Organization-ISO: DP 4049. Dental resin-based restorative materials 1985;6-10.

Jeng YR, Lina TT, Hsub HM, Chang HJ, Shieh DB. Human enamel rod presents anisotropic nanotribological properties. Journal of the Mechanical Behavior of Biomedical Materials $2001 ; 4: 515-22$.

Johansson AK, Sorvari R, Birkhed D, Meurman JH. Dental erosion in deciduous teeth - an in vivo and in vitro study. J Dent 2001;29:333-40.

Kinney JH, Marshall SJ, Marshall GW. The mechanical properties of human dentin: a critical review and re-evaluation of the dental literature. Crit Rev Oral Biol Med 2003;14:13-29.

Kodaka T, Debari K, Yamada M, Kuroiwa M. Correlation between microhardness and mineral content in sound human enamel. Caries Res 1992;26:139-41.

Kornblit R, Bossù M, Mari D, Rocca JP, Polimeni $A$. Enamel and dentine of deciduous teeth Er:YAG laser prepared. A SEM study. Eur J Paediatr Dent 2009;10:75-82.

Lakomaa EL, Rytömaa I. Mineral composition of enamel and dentin of primary and permanent teeth in Finland. Scand J Dent Res 1977;85:89-95.

Le Geros RZ, Glenn FB, Lee DD, Glenn WD. Some physico-chemical properties of deciduous enamel of children with and without pre-natal fluoride supplementation (PNF). J Dent Res $1985 ; 64: 465$.

Leventouri TH, Antonakos A, Kyriacou A, Venturelli R, Liarokapis E, Perdikatsis V. Crystal Structure Studies of Human Dental Apatite as a Function of Age. Int J Biomater 2009;1-6.

Linden LA, Bjõrkman S, Hattab F. The diffusion in vitro of fluoride and chlorhexidine in the enamel of human deciduous and permanent teeth. Arch Oral Biol 1986;31:33-7. 
Low IM, Duraman N, Davies IJ. Microstructure-Property relationships in human adult and baby canine teeth. Key Eng Mater 2006;23:309-11.

Low IM, Duraman N, Mahmood U. Mapping the structure, composition and mechanical properties of human teeth. Mater Sci Eng C 2008;28:243-47.

Lührs AK, Görmann B, Jacker-Guhr S, Geurtsen W. Repairability of dental siloranes in vitro. Dent Mater 2011;27:144-9.

Lussi A, Kohler N, Zero D, Schaffner M, Megert B. A comparison of the erosive potential of different beverages in primary and permanent teeth using an in vitro model. Eur J Oral Sci 2000;108:110-4.

Manson-Hing LR, Bloxon RM. A stepwedge quality assurance test for machine and processor in dental radiography. J Am Dent Assoc 1985;110:910-3.

Marquezan M, da Silveira BL, Burnett LH, Rodrigues CR, Kramer PF. Microtensile bond strength of contemporary adhesives to primary enamel and dentin. Clin Pediatr Dent 2008;32:127-32.

Mejàre I, Stenlund $\mathrm{H}$. Caries rates for the mesial surface of the first permanent molar and the distal surface of the second primary molar from 6 to 12 years of age in Sweden. Caries Res 2000;34:454-61.

Mortimer KV. The relationship of deciduous enamel structure of dental disease. Caries Res 1970;4:206-23.

Naujoks $R$, Schade $H$, Zelinka $F$. Chemical composition of different áreas of the enamel of deciduous and permanent teeth (The content of $\mathrm{Ca}, \mathrm{P}, \mathrm{CO}_{2}, \mathrm{Na}$ and $\mathrm{N}_{2}$ ). Caries Res $1967 ; 1: 137-43$.

Oliveira MAHM, Torres CP, Gomes-Silva JM, Chinelatti MA, Menezes FCH, Palma-Dibb RG, Borsatto MC. Microstructure and mineral composition of dental enamel of permanent and deciduous teeth. Microsc Res Tech 2010;73:572-77.

Pashley DH, Carvalho RM, Sano H, Nakajima M, Yoshiyama M, Shono Y, Fernandes CA, Tay FR. The micro-tensile bond test: A review. J Adhesive Dent 1999;1:299-309.

Pashley DH, Sano H, Ciucchi B, Yoshiyama M, Carvalho RM. Adhesion testing of dentin bonding agents: a review. Dent Mater 1995;11:117-25. 
Pécora JD, Souza Neto MD, Costa WF. Apresentação de um método químico que revela in vitro a passagem do peróxido de hidrogênio a $30 \%$ através da dentina radicular. Rev Paul Odontol 1991; 13:34-7.

Poole DFG, Tailby PW, Berry DC. The movement of water and other molecules through human enamel. Arch Oral Biol 1963;8:771-72.

Rasmussen ST, Patchin RE, Scott DB, Heuer HA. Fracture properties of human enamel and dentin. J Dent Res 1976;55:154.

Reitznerová E, Amarasiriwaardena D, Kopcakova M, Barnes RM. Determination of some trace elements in human tooth enamel. Fresenius J Anal Chem 2000;367:748-54.

Roy S, Basu B. Mechanical and tribological characterization of human tooth. Mater Character 2008;59:747-56.

Sano H, Ciucchi B, Matthews WG, Pashley DH. Tensile properties of mineralized and demineralized human and bovine dentin. J Dent Res 1994;73:1205-11.

Schiavoni RJ, Turssi CP, Rodrigues Jr AL, Serra MC, Pécora JD, Fröner IC. Assessing the effect of bleaching agents on enamel permeability. Am J Dent 2006;19:313-6.

Shellis RP. Variations in growth of the enamel crowns in human teeth and a possible relationship between growth and enamel structure. Arch Oral Biol 1984a;29:697-705.

Shellis RP. Relationship between human enamel structure and the formation of caries-like lesions in vitro. Arch Oral Biol 1984b;29:971-81.

Shimada Y, Senawongse P, Harnirattisai C, Burrow MF, Nakaoki Y, Tagami J. Bond strength of two adhesive systems to primary and permanent enamel. Oper Dent 2002;27:403-9.

Silverstone LM. The histopathology of early approximal caries in the enamel of primary teeth. ASDC J Dent Child 1970;37:17-26.

Smith CE. Cellular and chemical events during enamel maturation. Crit Rev Oral Biol Med 1998;9:128-61.

Sønju-Clasen AB, Ruyter IE. Quantitative determination of type A and type B carbonate in human deciduous and permanent enamel by means of Fourier Transform Infrared Spectrometry. Adv Dent Res 1997;11:523-7. 
Souza FCPP, Pardini LC, Cruvinel DR, Hamida HM, Garcia LF. In vitro comparison of the radiopacity of cavity lining materials with human dental structures. J Conserv Dent 2010;13:65-70.

Spears IR, Van Noort R, Crompton RH, Cardew GE, Howard IC. The effects of enamel anisotropy on the distribution of stress in a tooth. J Dent Res 1993;72:1526

Swanson TK, Feigal RJ, Tantbirojn D, Hodges JS. Effect of adhesive systems and bevel on enamel margin integrity in primary and permanent teeth. Pediatr Dent 2008;30:134-40.

Sydney-Zax M, Mayer I, Deutsch D. Carbonate content in developing human and bovine enamel. J Dent Res 1991;70:913.

Tagliaferro EPS, Lidiany Rodrigues LKA, Soares LES, Martin AA, Nobre-dos-Santos M. Physical and compositional changes on demineralized primary enamel induced by $\mathrm{CO}_{2}$ laser. Photomed Laser Surg 2009;27:585-90.

Ten Cate, A. R. Histologia Bucal- Desenvolvimento, Estrutura e Função. $5^{a}$ ed. Rio de Janeiro: Guanabara-Koogan; 2001.

Torres CP, Chinelatti MA, Gomes-Silva JM, Rizoli FA, Oliveira MAHM, Palma-Dibb RG, Borsatto MC. Surface and subsurface erosion of primary enamel by acid beverages over time. Braz Dent J 2010;21:337-45.

Turssi CP, Schiavoni RJ, Serra MC, Fröner IC. Permeability of enamel following light-activated power bleaching. Gen Dent 2006;54:323-6.

van Dijken JWV, Wing KR, Ruyter IE. An evaluation of the radiopacity of composite restorative materials used in Class I and II cavities. Acta Odontol Scand 1989;47:401-7.

Wang $L$, Tang R, Bonstein T, Bush P, Nancollas GH. Enamel demineralization in primary and permanent teeth. J Dent Res 2006;85:359-63.

Watts DC, McCabe JF. Aluminium radiopacity standards for dentistry: an international survey. J Dent 1999;27:73-8.

Wilson PR, Beynon AD. Mineralization differences between human deciduous and permanent enamel measured by quantitative microradiography. Arch Oral Biol 1989;34:85-8. 
Xu HHK, Smith DT, Jahanmir S, Romber E, Kelly JR, Thompson VP, Relow ED. Indentation damage and mechanical properties of human enamel and dentin. J Dent Res 1998;77:47280.

Zheng J, Zhou ZR. Effect of age on the friction and wear behaviors of human teeth. Tribol Intern 2006,39:266-73. 
$\frac{1}{2}$ 


\section{ANeXo A - Aprovação do Comitê de ÉTICA}

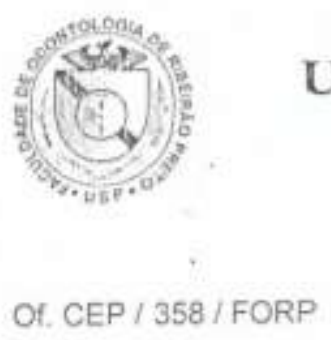

\section{UNIVERSIDADE DE SÃO PAULO}

Faculdade de Odontologia de Ribeirāo Preto Counifedelitica $\mathrm{cm}$ P'serpuisa

Ribeirâo Preto, 25 de agosto de 2010

Ref. processo n." 2010.1.542.58.1

CAAE n. ${ }^{\circ} 0033,0.138,000-10$

Senhora Pesquisadora,

Informamos que o Comité de Etica em Pesquisa, em sua 111. sessảo, realizada em 19/08/2010, aprovou o desenvolvimento do projeto de pesquisa envolvendo seres humanos, intituiado "Analise das propriadades marfo-estmturais e fisicoquimicas do esmalte de dentes deciduos e permanentes - estudo in vïtro".

$\mathrm{Na}$ oportunidade, lembramos da necessidade de serem entregues, na secretaria do CEP, o Relatório Parcial em 19/08/2011 e o Relatório Final em 19/08/2012. com os respectivos formulários preenchidos pelo pesquisador responsavel

Lembramos ainda que, quando da submissão dos relatórios a este Comitê, quaisquer inclusôes ou modificaçôes no projeto original deverào ser comunicadas e justificadas ao CEP, através do formulário supracitado

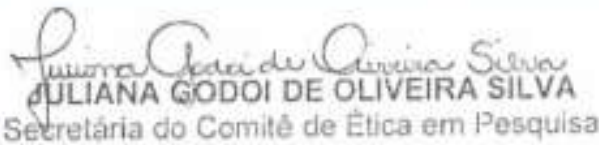

IIma. Sra.

Recebi Original

PG. JACIARA MIRANDA GOMES DA SILVA

Departamento de Clinica Infantil, Odontologia Preventiva e Social desta Faculdade

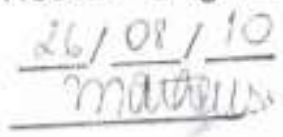

